\title{
Evolution in Value Relevance of Accounting Information
}

\author{
(For best results, please print in color)
}

Mary E. Barth

Ken $\mathrm{Li}^{\mathrm{b}}$

Charles G. McClure ${ }^{\mathrm{c}}$

December 2019

We thank Susan Athey, Greg Clinch, Yiwei Dou, Rebecca Hann, Bob Holthausen, Guido Imbens, Chris Ittner, Bjorn Jorgensen, Jian Kang, Lester Mackey, Thomas Scott, Eric So, Catalin Starica, Mary Tokar, Youfei Xiao, and seminar participants at Cass Business School; ESSEC Business School; European Accounting Association Annual Congress; Information, Markets, and Organizations Conference at Harvard Business School, especially Trevor Harris, discussant; Indiana University; the International Accounting Standards Board; London School of Economics; University of Melbourne; University of Michigan; Michigan State University; New York University; University of Oxford; and Stanford University for helpful comments and suggestions. This work is supported by the Graduate School of Business at Stanford University and the FMC Faculty Fund at the University of Chicago Booth School of Business.

\footnotetext{
${ }^{a}$ Corresponding author. Graduate School of Business, Stanford University, 655 Knight Way, Stanford, CA 94305. Email: mbarth@stanford.edu

${ }^{\mathrm{b}}$ DeGroote School of Business, McMaster University, 1280 Main Street West, Hamilton, ON, L8S 4M4, Canada

${ }^{c}$ University of Chicago, Booth School of Business, 5807 S. Woodlawn Ave., Chicago, IL 60637
} 


\title{
Evolution in Value Relevance of Accounting Information
}

\begin{abstract}
We address how value relevance of accounting information evolved as the new economy developed. Prior research concludes accounting information - primarily earnings - has lost relevance. We consider more accounting amounts and find no decline in combined value relevance from 1962 to 2014. We assess evolution in each amount's value relevance and find increases, most notably for amounts related to intangible assets, growth opportunities, and alternative performance measures, which are important in the new economy. The number of relevant amounts also increases. We also consider separately new economy, non-new economy profit, and non-new economy loss firms. The relevance trends are more pronounced for, but extend beyond, new economy firms. We base inferences on a non-parametric approach that automatically incorporates nonlinearities and interactions, thereby unconstraining the valuation relation. Taken together, our findings reveal a more nuanced, but not declining, relation between share price and accounting information that reflects the new economy.
\end{abstract}

JEL classification: C14, G10, G18, M40, M41

Keywords: Capital Markets; Equity Valuation; Financial Reporting; Value Relevance; New Economy; Classification and Regression Trees; 


\section{Evolution in Value Relevance of Accounting Information}

\section{Introduction}

The question we address is how the value relevance of accounting information evolved as the economy transitioned from primarily industrial to a "new economy" based on services and information technology. Prior research finds value relevance of accounting amountsparticularly earnings - has declined, attributes the decline to the rise of this new economy, and concludes accounting information has lost its relevance. ${ }^{1}$ We consider value relevance of a larger set of accounting amounts, including amounts that could reflect information about intangible assets, growth opportunities, and alternative firm performance measures, which are important in the new economy. We find increases in relevance of these accounting amounts combine to offset earnings' relevance decline. We also find that although these trends are more pronounced for firms emblematic of the new economy, they also extend beyond new economy firms. Our findings reveal an evolution in value relevance of accounting information to a more nuanced, not declining, relation between accounting amounts and share price that reflects equity valuation in the new economy.

Understanding the evolution in value relevance of accounting information provides insights into whether accounting is relevant in the new economy. This is not a given because accounting developed when the US economy largely comprised industrial firms and has not changed fundamentally since then. It is well-known that current accounting does not include intangible asset values, does not attempt to reflect growth opportunities, and emphasizes a single performance measure, namely earnings. Determining the evolution in value relevance of

\footnotetext{
${ }^{1}$ Consistent with prior research, we define an accounting amount as value relevant if it explains variation in share price (Barth, Beaver, and Landsman 2001). We use the terms net income and earnings interchangeably.
} 
individual accounting amounts reveals the extent to which each amount has become more and less relevant. Thus, our findings provide insights into how accounting information reflects, and might be enhanced to reflect better, information investors use when assessing firm value and provide insights potentially relevant to equity valuation. In particular, finding increased relevance of accounting amounts relating to intangible assets, growth opportunities, and alternative performance measures—despite incomplete reflection in accounting—reveals these categories of information are relevant to investors in the new economy.

We base our inferences on annual relations between equity price and accounting amounts from 1962 to 2014, and measure value relevance as the explanatory power of the estimated relation. Prior research largely estimates a linear relation, and does not identify precisely how each accounting amount maps into future cash flows and therefore into equity value. Thus, imposing a particular functional form could understate the accounting amounts' explanatory power and, consequently, their value relevance. In contrast, we employ a flexible, nonparametric estimation approach—Classification and Regression Trees (CART)—that automatically incorporates any nonlinearities and interactions, thereby permitting the accounting amounts' value relevance to manifest more fully.

We measure value relevance using out-of-sample explanatory power because in-sample explanatory power can overstate value relevance. We find CART's average out-of-sample explanatory power across years is higher than that of a relation that is linear in the accounting amounts and includes interactions with industry membership and whether the firm reports a loss $-69.8 \%$ versus $27.9 \%$. Strikingly, the in-sample explanatory power of latter specificationwhich is not uncommon in accounting research-averages $71.8 \%$, which indicates it is substantially overstated and basing inferences on in-sample explanatory power can be misleading 
when the specification includes many variables. We also find the out-of-sample explanatory power of a linear relation that includes only earnings and equity book value averages $55.7 \%$. The higher explanatory power for CART $-69.8 \%$ versus $55.7 \%$-reflects additional explanatory power associated with more accounting amounts and inclusion of nonlinearities and interactions.

The accounting amounts we consider are net income and equity book value, fourteen other amounts presented in financial statements throughout our sample period that prior research finds are value relevant, and ten industry indicators (hereafter, "accounting amounts"). Although prior research assessing trends in value relevance of accounting information considers some of these amounts, no study considers them all. Also, we are unaware of studies that assess trends in value relevance of individual accounting amounts, other than earnings and equity book value.

Relating to intangible assets we consider research and development expense, recognized intangible assets, and advertising expense, and relating to growth opportunities we consider cash and revenue growth. Relating to alternative performance measures we consider operating cash flow and revenue, and we consider special items and other comprehensive income because they often are excluded when constructing non-GAAP performance measures such as Street earnings. We also consider dividends, capital expenditures, cost of goods sold (COGS), selling, general, and administrative expense (SGA), and total assets. We include industry indicators to allow the relation between price and the accounting amounts to vary across industries, which prior research shows is important.

We first re-examine the conclusion of prior research that the value relevance of accounting information has declined. We do not expect a decline because we consider more accounting amounts and employ a flexible, non-parametric estimation method. Consistent with this expectation, we find no evidence of a significant decline in value relevance of accounting 
information across all years or in any decade other than the 1990s, which coincides with the technology bubble. If anything, we find some evidence of an increase. Thus, in contrast to the overall conclusion from prior research, our findings do not support a conclusion that the value relevance of accounting information has declined.

We next determine how much of combined value relevance derives from each accounting amount. This determination permits us to provide insights into how individual amounts contribute to the evolution in value relevance of accounting information. Based on prior research, we expect the relevance of earnings to decline and that of equity book value to increase. We find that they do. More importantly for our research question, we expect accounting amounts related to intangible assets, growth opportunities, and alternative performance measures to become more relevant. Consistent with these expectations, we find significant increases in relevance of research and development expense, recognized intangible assets, cash, revenue growth, operating cash flow, revenue, and special items.

Because prior research finds a decline in the number of dividend-paying firms, we expect the relevance of dividends to decline. We find that it does. Although we have no expectations regarding trends in relevance of the remaining accounting amounts, we find a significant decline (increase) in relevance of COGS and total assets (capital expenditure). We also find a significant increase in the number of accounting amounts needed to explain the same proportion of combined value relevance, which indicates more accounting amounts reflect information in price and suggests valuations have become more nuanced.

We next examine the evolution in value relevance of individual accounting amounts separately for New Economy firms, Non-New Economy Profit firms, and Non-New Economy Loss firms. New Economy firms are those with characteristics prior research identifies as 
emblematic of firms in the new economy, namely operating in a technology industry or reporting a loss in the year of its IPO (initial public offering). We separate Non-New Economy firms into those reporting a profit and those reporting a loss because prior research shows accounting amounts - particularly earnings — of profit and loss firms have different relations with price, and loss firms are notoriously difficult to value. Over the last five decades the economy proportions of New Economy firms and Non-New Economy Loss firms significantly increased. Although the proportion of Non-New Economy Profit firms significantly decreased, these firms represent the largest proportion of firms in the economy.

Regarding value relevance of earnings, we find its relevance has declined for New Economy firms and Non-New Economy Profit firms. As expected, we find the decline is more dramatic for New Economy firms. Not surprisingly, we find earnings has little relevance for Non-New Economy Loss firms. Thus, the increase in proportion of New Economy and NonNew Economy Loss firms contributes to earnings' value relevance decline in the full sample.

Regarding value relevance of accounting amounts relating to intangible assets, growth opportunities, and alternative performance measures, we find that the average value relevance of intangible assets is higher for New Economy firms than in the full sample. We also find that increases in value relevance relating to growth opportunities and alternative performance measures are more pronounced for New Economy firms. However, these increasing trends are also apparent for Non-New Economy Profit firms. These findings suggest firms emblematic of the new economy are not solely responsible for the relevance increases. Rather, they extend beyond new economy firms.

The remainder of the paper proceeds as follows. Section 2 relates our study to prior research, and describes the accounting amounts and our predictions. Section 3 develops the 
research design. Section 4 describes the sample and data and section 5 presents the findings.

Section 6 presents additional analyses and section 7 concludes.

\section{Related literature, accounting amounts, and predictions}

\subsection{Research on trends in value relevance of accounting amounts}

A large literature documents a decline in earnings' value relevance and offers two primary explanations for the decline. The first is the rise of the new economy in which future earnings largely depends on investments in intangible assets. Investments in intangible assets typically are expensed as incurred even though the investments generate economic benefits over a longer period, which negatively affects earnings quality. Lev and Zarowin (1999) finds a weaker association between price and earnings for firms with more intangible assets and attributes this finding to the timing mismatch of expenses and revenue associated with such assets. Consistent with a decrease in matching, Dichev and Tang (2008) finds a decrease in the correlation between revenue and expenses. Donelson, Jennings, and McInnis (2011) and Srivastava (2014) suggest the decline in matching is attributable to changes in the economy, such as an increase in the number of new firms with business models focused on intangible assets. ${ }^{2}$ The second explanation is the presence of more loss firms. Hayn (1995) and Collins, Pincus, and Xie (1999) find earnings is less relevant for loss firms, and Barth, Beaver, and Landsman (1998) finds the relevance of net income (equity book value) decreases (increases) as a firm's financial health decreases. Thus, Collins et al. (1999) suggests the presence of more loss firms explain earnings' relevance decline. ${ }^{3}$

\footnotetext{
${ }^{2}$ Dichev and Tang (2008) explains matching could have declined because of changes in the economy or changes in accounting standards. As is Dichev and Tang (2008), we are interested in the combined effect of these changes because both influence the extent to which accounting amounts reflect information investors use to value firms. ${ }^{3}$ A third explanation is increased noise in equity prices. Brunnermeier and Nagel (2004) finds hedge funds traded against fundamentals from 1998 to 2000, which was the height of the technology bubble, and Dontoh, Radhakrishnan, and Ronen (2004) posits this increased presence of noise traders exacerbates the decline in value
} 
Collins, Maydew, and Weiss (1997) suggests that although shifts in the economy towards technology and loss firms could explain the decline in earnings' relevance, these shifts could increase equity book value's relevance. This could occur because equity book value predicts future normal earnings and reflects loss firms' abandonment option (Barth et al. 1998a; Collins et al. 1999). Consistent with this logic, Collins et al. (1997) and Francis and Schipper (1999) find earnings' value relevance decline is offset by an increase in equity book value's relevance. Brown, Lo, and Lys (1999) also finds a decline (an increase) in value relevance of earnings (equity book value) from the late 1950s to the late 1990s, but finds a decline in their combined relevance after including controls for scale effects. Lev and Zarowin (1999) and Balachandran and Mohanram (2011) find a decline in combined value relevance of earnings and equity book value from the late 1970s to the early 2000s.

Studies considering accounting amounts in addition to earnings and equity book value also find a decline in value relevance of accounting information. Core, Guay, and Van Buskirk (2003) considers research and development expense, advertising expense, capital expenditure, and revenue growth in addition to earnings and equity book value, and finds their combined value relevance is lower from 1996 to 1999 than from 1975 to 1995. Core et al. (2003) explains that revenue growth is included because valuation of high technology firms is influenced by future growth opportunities to a greater extent than other firms. Lev and Gu (2016) considers earnings and assets and liabilities — thereby, indirectly, equity book value — and selected components of earnings, namely revenue, COGS, and SGA, and finds a decline in their

relevance of accounting information because such traders do not trade based on fundamental information. Consistent with this explanation, Core, Guay, and Van Buskirk (2003) finds the value relevance of the accounting amounts that study considers is lower from 1996 to 1999 than in prior periods, but the accounting amounts' coefficients are stable. Core et al. (2003) interprets these findings as indicating the lower value relevance is attributable to increases in price and returns variances unrelated to accounting information. 
combined value relevance from 1950 to 2013. Based on this evidence, Lev and Gu (2016)

proclaims the "end of accounting." However, other studies find accounting amounts these studies do not consider also are value relevant (Barth et al. 2001; Holthausen and Watts 2001). Thus, the overall inference of a decline in relevance of accounting information could result from failure to consider these amounts. ${ }^{4}$

We contribute to this literature in four primary ways. First, we assess evolution in combined value relevance of accounting information using more accounting amounts, including some that reflect information relevant in the new economy. Second, we assess evolution in value relevance for each accounting amount to provide direct evidence on which amounts have increased and declined in relevance. Third, we assess evolution in value relevance of each accounting amount separately for new economy, non-new economy profit, and non-new economy loss firms to determine the extent to which trends in relevance are economy-wide. Fourth, we measure value relevance as the out-of-sample explanatory power of the relation between price and accounting amounts estimated using a flexible, non-parametric approach that automatically incorporates nonlinearities and interactions, thereby permitting the accounting amounts' value relevance to manifest more fully.

\subsection{Accounting amounts and predictions}

This section identifies the accounting amounts we consider, explains why we consider them, and provides our expectations as to trends in their value relevance. In brief, we consider amounts from prior research on trends in value relevance of accounting information, as well as amounts presented in financial statements throughout our sample period that prior research finds

\footnotetext{
${ }^{4}$ Davern, Gyles, Hanlon, and Pinnuck (2018) finds no decline in value relevance of earnings and equity book value for Australian firms from 1992 to 2015, but finds EBIT and EBITDA are more value relevant than earnings. From 1996 to 2014, Filip, Ghio, and Paugam (2018) finds earnings (cash flow) relevance is lower (higher) for innovative Small and Medium Entities (SMEs) listed on the AIM London Stock exchange than for non-innovative SMEs.
} 
are value relevant. These include net income and equity book value, fourteen other amounts presented in financial statements, and ten industry indicators. ${ }^{5}$

Before assessing trends in individual accounting amounts, we re-examine the conclusion in prior research that the value relevance of accounting information has declined. We do not expect to find a decline because we consider more accounting amounts, some of which could reflect information relevant in the new economy, and we employ a flexible, non-parametric estimation method. However, our expectations may not be borne out because current accounting does not include intangible asset values, does not attempt to reflect growth opportunities, and emphasizes a single performance measure, namely earnings. Thus, accounting amounts might not reflect information relevant to valuing firms in the new economy.

2.2.1 Net income and equity book value

Following a large literature in accounting, we consider net income and equity book value, the two primary accounting summary measures. Miller and Modigliani (1966) and Ohlson (1995) theoretically support considering these amounts. Based on the prior research in section 2.1, we expect the relevance of earnings (equity book value) to decline (increase).

\subsubsection{Intangible assets}

Regarding intangible assets, we consider research and development expense and advertising expense because Core et al. (2003) suggests these accounting amounts reflect expected future earnings growth associated with investments in intangible assets. Lev and Sougiannis (1996) finds research and development and advertising expenses have positive relations with future operating earnings because these expenses indicate investments in

\footnotetext{
${ }^{5}$ In principle, we could include all accounting amounts. However, each additional amount increases estimation complexity at an ever increasing rate, which places practical limits on the number of amounts we can include (Breiman 2001). In addition, many accounting amounts are missing for large portions of our sample period.
} 
technological innovation and brand awareness. Barth, Clement, Foster, and Kasznik (1998) finds advertising expense is associated with brand values, which are value relevant. We also consider recognized intangible assets. Aboody and Lev (1998) finds capitalized software development costs - a type of recognized intangible asset — is associated with future earnings, which suggests recognized intangible assets are value relevant. We expect these accounting amounts to become more relevant with the rise of the new economy in which intangible assets are important to firm value. However, our expectations might not be borne out because these accounting amounts are not designed to capture intangible asset values, e.g., advertising expense is not designed to capture brand value.

\subsubsection{Growth opportunities}

Regarding amounts that reflect information about growth opportunities, we consider cash and revenue growth. Myers and Majluf (1984) suggests cash is more valuable when external financing is costly and the firm has positive net present value projects. Opler, Pinkowitz, Stulz, and Williamson (1999) finds firms with more growth opportunities hold more cash, which suggests cash is more relevant for growth firms. Faulkender and Wang (2006) finds the marginal value of cash is higher for firms with valuable investment opportunities and financial constraints. Revenue growth captures expected growth in earnings (Core et al. 2003). We expect these accounting amounts become more relevant with the rise of the new economy in which growth opportunities are important to firm value. However, our expectations might not be borne out because accounting amounts are not designed to capture, and thus likely incompletely reflect, growth opportunities.

\subsubsection{Alternative performance measures}


Regarding performance measure alternatives to earnings, we consider operating cash flow because it is an alternative to earnings when predicting future cash flows (e.g., Palepu and Healy 2008). Operating cash flow also can be more persistent than earnings and predict future earnings incremental to current earnings (Sloan 1996; Barth, Beaver, Hand, and Landsman 1999). Also, including operating cash flow together with earnings effectively includes accruals. We consider revenue because it is particularly relevant for internet and loss firms (Davis 2002; Callen, Robb, and Segal 2008), and Ertimur, Livnat, and Martikainen (2003) finds revenue is more persistent than expenses.

We consider two other earnings components prior literature suggests have implications for future cash flows that differ from earnings. The first is special items, which are less persistent than other earnings components. Jones and Smith (2011) finds special items help predict future net income and operating cash flow incremental to current net income. Collins et al. (1997) documents that special items have increased, and suggests this increase could reduce the value relevance of earnings. In addition, Bradshaw and Sloan (2002) and Bhattacharya, Black, Christensen, and Larson (2003) find there is an increase in firms' use of non-GAAP earnings, which excludes unusual or non-recurring items, i.e., special items. Bradshaw and Sloan (2002) also documents an increase in analyst Street earnings, which also generally excludes special items. Including special items effectively includes earnings before special items, which is substantially similar to operating earnings in Bhattacharya et al. (2003).

The second is other comprehensive income (OCI) because, as with special items, Jones and Smith (2011) finds OCI has predictive power for future net income and operating cash flow incremental to earnings. Jones and Smith (2011) observes OCI recognition of gains and losses has increased, and firms and analysts often ignore OCI when constructing non-GAAP and Street 
earnings. Including OCI in the accounting amounts effectively includes comprehensive income because comprehensive income is the sum of net income and OCI. ${ }^{6}$

We expect an increase in value relevance of accounting amounts relating to alternative performance measures for the reasons outlined above and given the decline in earnings quality documented in prior research discussed in section 2.1. Our expectations might not be borne out because, incremental to earnings, these accounting amounts might not reflect the performance measures investors use when valuing the firm.

\subsubsection{Other amounts}

We also consider dividends, capital expenditure, COGS, SGA, total assets, and industry indicators. Miller and Rock (1985) suggests dividends can be a signal about, and thus help predict, future earnings in the presence of information asymmetry, thereby making dividends relevant to firm value. Consistent with this suggestion, Watts (1973) finds a positive association between dividends and future earnings. In addition, financial statement analysis textbooks suggest dividend discount and dividend growth models can be appropriate for estimating firm value (Palepu and Healy 2008). However, Floyd, Li, and Skinner (2015) finds a decrease from 1980 to 2012 in the propensity for firms, other than banks, to pay dividends, which leads us to expect dividends' relevance to decline. However, our expectations might not be borne out if firms' decreased propensity to pay dividends increases their relevance for firms that pay them.

Capital expenditure reflects investments in tangible assets. If tangible assets become more important for firm value, capital expenditure could become more relevant. However, if the new economy's focus is only on intangible assets, capital expenditure could become less

\footnotetext{
${ }^{6}$ Dhaliwal, Subramanyam, and Trezevant (1999) finds OCI has higher value relevance than net income for some segments of the economy, such as financial firms, largely because OCI includes unrealized gains and losses on marketable securities.
} 
relevant. COGS and SGA can have implications for future earnings different from current earnings (Lev and Gu 2016). Including assets effectively includes liabilities because liabilities is the difference between assets and equity book value. Also, as section 3.1 explains, when using CART including assets effectively includes asset-based ratios, such as return-on-assets and salesto-assets ratios, which prior research finds are relevant (Ou and Penman 1989). However, we have no expectations regarding relevance trends for capital expenditure, COGS, SGA, or assets.

We include industry indicators because how accounting amounts map into firm value differs for firms in different industries. Thus, it is common in value relevance research to estimate valuation equations separately by industry (Barth et al. 1999). Also, as section 3 explains, when using CART, including industry indicators not only permits the relations between the accounting amounts and price to vary across industries, but also enables the relations to reflect interactions and nonlinearities between industry membership and the accounting amounts. We have no expectation regarding value relevance of the industry indicators. If heterogeneity in the relations between price and accounting amounts across industries increases, industry indicators could become more relevant. If heterogeneity does not increase or other accounting amounts, such as research and development expense, better capture the increase, the indicators could become less relevant.

\section{Research design}

\subsection{Estimating value relevance}

To assess the evolution in value relevance of accounting information, we estimate, by year, the relation between price and accounting amounts specified Equation (1), and examine the trend over time in its explanatory power.

$$
P_{i}=\operatorname{CART}\left(V A R_{i}, I N D 10_{i}\right)
$$


$P$ is share price, $V A R$ is a vector of sixteen accounting amounts other than industry indicators, and $I N D 10$ is a set of indicator variables for the Fama-French ten industry groups. VAR comprises earnings, $N I$; equity book value, $B V E$; research and development expense, $R D$; recognized intangible assets, including capitalized software, goodwill, and other purchased intangible assets, INTAN; advertising expense, $A D V$; cash, cash equivalents, and short-term investments, $C A S H$; one-year revenue growth, REVGR; operating cash flow, $C F$; revenue, $R E V$; special items, SPI; other comprehensive income, OCI; declared dividends to common shareholders, DIV; capital expenditures, CAPX; cost of goods sold, COGS; selling, general, and administrative expense, SGA; and total assets, ASSETS. See Appendix 1 for variable definitions. We measure price three months after fiscal year-end to ensure the accounting information is publicly available. ${ }^{7}$ We deflate non-indicator amounts by shares outstanding to facilitate comparison with several related prior studies (Collins et al. 1997; Brown et al. 1999; Lev and Zarowin 1999; Balachandran and Mohanram 2011). ${ }^{8}$ Subscript $i$ indexes firms.

CART is the Classification and Regression Trees (CART) estimation function, which is akin to a decision tree. ${ }^{9}$ Appendix 2 explains CART estimation. In brief, CART is a nonparametric estimation approach that does not require the researcher to specify—and, thus potentially inappropriately constrain — the relation's functional form. CART identifies nonlinearities in the underlying relation and interactions between and among the explanatory

\footnotetext{
${ }^{7}$ Although investors can obtain information about firm value from financial statements or from other sources, our value relevance metric reflects only the extent to which the accounting amounts, and information correlated with them, explain price (Barth, Konchitchki, and Landsman 2013).

${ }^{8}$ See section 6.2 for a discussion of findings based on deflation by beginning-of-year price (Brown et al. 1999).

${ }^{9}$ CART is part of a family of decision tree-based estimation methods that can increase explanatory power relative to traditional linear methods, detect relative importance of explanatory variables, and uncover nonlinearities and interactions in the marginal relations between the independent and dependent variables (Breiman 2001). These methods are used in a variety of non-accounting research settings, including facial recognition, spam e-mail detection, and disease diagnosis (see Verikas, Gelzinis, and Bacauskiene 2011 for a review), and in accounting research (Gerakos, Hahn, Kovrijynkh, and Zhou 2016; Correia, Kang, and Richardson 2017; Jones 2017; Beaver, Cascino, Correia, and McNichols 2018).
} 
variables by recursively partitioning the variables, and automatically incorporates nonlinearities and interactions that increase the relation's out-of-sample explanatory power. These nonlinearities and interactions effectively permit the relation between any explanatory variable and price to vary as an unconstrained function of any of the other variables and to include any ratios based on the explanatory variables. The absence of researcher-imposed constraints on the relation is important because with potential nonlinearities and interactions in the underlying relation, estimation that assumes an additively linear structure in the explanatory variables, except for particular nonlinearities and interactions the researcher specifies, such as OLS, is susceptible to understating value relevance (Hastie, Tibshirani, and Friedman 2001).

Even though researchers can specify known nonlinearities and interactions, more are possible (Holthausen and Watts 2001). For example, Riffe and Thomson (1998) shows the relation between price and earnings (equity book value) can be nonlinear when earnings (equity book value) captures economic earnings (equity book value) with error. Yee (2000) shows a nonlinear relation between price and earnings can exist when firms adapt to their competitive environment. Kumar and Krishnan (2008) shows that the value relevance of earnings varies non-linearly based on the level of investment opportunities. However, Riffe and Thompson (1998) and Yee (2000) observe that unmodeled nonlinearities likely exist. ${ }^{10}$

Our value relevance metric is the out-of-sample $\mathrm{R}^{2}\left(\mathrm{OOS} \mathrm{R}^{2}\right)$ from Equation (1). We rely on OOS $\mathrm{R}^{2}$ because when there are many explanatory variables relative to the number of observations, in-sample adjusted $\mathrm{R}^{2}$, which is a commonly used value relevance metric, is

\footnotetext{
${ }^{10}$ As section 2.1 explains, Collins et al. (1999) finds a flat relation between earnings and price for loss firms, but a positive relation for profit firms. Barth et al. (1998a) finds valuation coefficients on earnings and equity book value differ as a function of firms' financial health. Faulkender and Wang (2006) finds firms with high growth opportunities have a higher marginal value of cash. Also, a substantial literature examines the explanatory power of various financial ratios, which are nonlinear transformations of accounting amounts (Ou and Penman 1989).
} 
susceptible to overstating value relevance (Hastie et al. 2001). This occurs because with many explanatory variables the estimation reflects sample characteristics rather than the underlying relation. Thus, removing a few observations, re-estimating the equation using the remaining observations, and using the resulting coefficient estimates to predict price for the removed observations would result in poor predictive power. OOS $\mathrm{R}^{2}$ reveals such overstatement.

CART avoids overstating value relevance by bootstrapping the sample, estimating a tree over each bootstrapped sample, using the tree from each bootstrapped sample to predict price for out-of-sample observations, and comparing out-of-sample price predictions-averaged across bootstrapped samples — with actual price to estimate explanatory power. Fitting the equation using a portion of the observations in each bootstrapped estimation and averaging estimates of predicted price reduces noise in the estimated underlying relation. ${ }^{11}$ Because our implementation of CART is estimated over bootstrapped samples, in-sample $\mathrm{R}^{2}$ is not well-defined.

To provide evidence that CART's flexibility enables the accounting amounts' value relevance to manifest more fully, Appendix 2 reveals CART has higher mean OOS $\mathrm{R}^{2}$ across all years-69.8\% - than two specifications commonly used in prior research. Mean out-of-sample explanatory power is only $27.9 \%$ for OLS estimation of a specification that is linear in the accounting amounts and includes interactions with industry and loss indicators. Mean in-sample explanatory power for that specification is $71.8 \%$, which indicates in-sample explanatory power is substantially overstated. Mean out-of-sample explanatory power is $55.7 \%$ for OLS estimation of a linear relation between price and earnings and equity book value. Its mean in-sample

\footnotetext{
${ }^{11}$ CART estimation provides insights into value relevance trends, but has several limitations. First, although CART automatically determines nonlinearities and interactions, it is difficult to visualize the estimated prediction function. Thus, the tabulated findings and figures do not summarize all significant relations underlying the CART prediction function. Figure A2.1 displays one tree used in the estimation. Second, using CART precludes us from summarizing findings in the form of coefficient estimates and confidence intervals. Appendix 2 provides examples of nonlinearities in Equation (1) that CART identifies.
} 
explanatory power is $55.9 \%$, which indicates less overstatement of explanatory power with only two accounting amounts. The $14.1 \%(69.8 \%-55.7 \%)$ higher OOS $\mathrm{R}^{2}$ for CART for this specification reflects the additional explanatory power associated with more accounting amounts and the inclusion of unspecified nonlinearities and interactions. ${ }^{12}$

\subsection{Evolution in combined value relevance of accounting amounts}

To test for a trend in combined value relevance, we estimate Equation (2).

$$
\operatorname{OOSR} 2_{t}=\beta_{0}+\beta_{1} Y E A R_{t}+\varepsilon_{t}
$$

OOSR2 is OOS $\mathrm{R}^{2}$ estimated from Equation (1), and YEAR is year of the observation, 1962,..., 2014. $t$ denotes year. Because we expect no decline in relevance of accounting information, we expect $\beta_{1}$ is positive or insignificantly different from zero.

\subsection{Evolution in value relevance of each accounting amount}

We next disaggregate each annual OOS $\mathrm{R}^{2}$ to determine how much value relevance derives from each accounting amount. We test whether an accounting amount's relevance has increased or declined by estimating Equation (3).

$$
V R_{k t}=\beta_{0}+\beta_{1} Y E A R_{t}+\varepsilon_{t}
$$

$V R_{k}$ is accounting amount $k$ 's value relevance. When we expect an accounting amount has become more (less) relevant, we expect $\beta_{1}$ is positive (negative).

$V R_{k}$ is the percentage of OOS $\mathrm{R}^{2}$ attributable to accounting amount $k$. To construct $V R_{k}$, we determine how much combined value relevance decreases when we randomly assign each accounting amount one at a time, relative to the other amounts. ${ }^{13}$ For example, if we randomly

\footnotetext{
${ }^{12}$ To validate that CART does not spuriously generate high OOS R${ }^{2}$, we estimate Equation (1) for each year from 1962 to 2014 using prices selected randomly, with replacement, from the sample of actual prices for that year. The untabulated findings reveal the OOS $\mathrm{R}^{2}$ is negative in every year, and the across-year mean is $-5.6 \%$.

${ }^{13}$ Random assignment is equivalent to omitting the amount from the estimation because it results in the amount having no systematic relation with price or any other accounting amount. Thus, $V R_{k}$ is analogous to the incremental $\mathrm{R}^{2}$ of variable $k$. However, in CART estimation $V R$ reflects the myriad ways in which an accounting amount is value relevant, e.g., as a main effect, an interaction effect, and a nonlinearity effect, including its role in ratios.
} 
assign $N I$ and the resulting $\mathrm{OOS}^{2}$ is less than if we randomly assign $B V E$, then $N I$ is more value relevant than $B V E .^{14}$ We also estimate Equation (3) using the sum of $V R_{k}$ for amounts related to intangible assets, Intans - RD, INTAN, and $A D V$; growth opportunities, Growth$C A S H$ and $R E V G R$; and alternative performance measures, AltPerf-CF, REV, SPI, and $O C I$.

To test for trends in the number of value relevant amounts, we estimate Equation (4):

$$
N U M V R_{t}=\beta_{0}+\beta_{1} Y E A R_{t}+\varepsilon_{t}
$$

NUMVR is the number of relevant accounting amounts in year $t$ based on a specified relevance threshold. In particular, we order the amounts by $V R$ and, beginning with the amount with the highest $V R$, we add amounts until they together explain $50 \%, 75 \%, 80 \%, 90 \%$, and $95 \%$ of combined value relevance. ${ }^{15}$ We interpret positive $\beta_{1}$ as an increase in the nuance with which price reflects accounting information.

\subsection{Evolution in value relevance of accounting amounts by firm groups}

We estimate the accounting amounts' relevance separately for three groups of firms to provide insights into the extent to which the evolution in combined value relevance applies only to firms emblematic of the new economy or is economy wide. For these estimations, the sample period begins in 1971 to ensure a sufficient number of observations in each year and group.

The first group is New Economy firms. Prior research identifies technology industry, loss, and newer cohorts of firms as emblematic of the new economy (Collins et al. 1997; Francis and Schipper 1999; Core et al. 2003; Srivastava, 2014). Consistent with these characteristics, we classify a firm as a New Economy firm if it is in a technology industry or had its IPO in 1971 or

\footnotetext{
${ }^{14}$ As an example, assume the combined explanatory power of $N I$ and $B V E$ is 0.90 . Also assume that if $N I(B V E)$ is randomly assigned, the explanatory power is $0.30(0.70)$, which means if $N I(B V E)$ is randomly assigned the explanatory power decreases by $0.60(0.20)[0.90-0.30(0.90-0.70)]$. Thus, the value relevance of $N I$ is 0.75 $[0.60 /(0.60+0.20)]$, and that of $B V E$ is $0.25[0.20 /(0.60+0.20)]$. We randomly assign one variable at a time to assess its value relevance, except for the industry indicators, for which we randomly assign individually, assess decreases in combined value relevance, and consider the sum of the decreases across all industry indicators together. 15 There is no standardized threshold for tests of value relevance of accounting amounts; we use these five.
} 
later and reported a loss in the year of its IPO. ${ }^{16}$ The second and third groups are Non-New Economy Profit and Non-New Economy Loss firms. We distinguish profit and loss firms because prior research finds earnings has higher (lower) relevance for profit (loss) firms. In addition, loss firms are notoriously difficult to value (Joos and Plesko 2005; Darrough and Ye 2007). We provide insights into which accounting amounts reflect investors' assessments of value for these firms. ${ }^{17}$

\section{Sample and descriptive statistics}

The sample comprises 227,030 firm-year observations from Compustat and CRSP from 1962 to 2014. We begin in 1962 when Compustat began its service (Fama and French 1992; 1993; 2015). Although Compustat backfilled data prior to 1962, those data reflect selection bias and coverage is tilted towards successful firms (Fama and French 1992; Linnainmaa and Roberts 2016). Beginning in 1962 also enables us to detect trends associated with the shift to the new economy, which is evident by the 1970s (Buera and Kaboski 2012). Ending the sample in 2014 means the sample period covers a variety of economic conditions, including the 2007-2008 financial crisis and the technology bubble, which we find is associated with a drop and subsequent recovery in combined value relevance.

\footnotetext{
${ }^{16}$ Technology firms are those in three-digit SIC industries with large unrecognized intangible assets, specifically industries 283, 357, 360-368, 481, 737, and 873 (Francis and Schipper 1999; Core et al. 2003), which include computer hardware and software, pharmaceuticals, electronic equipment, and telecommunications. Loss firms have negative earnings. The year of a firm's IPO would be, for example, 2012 (2013) for a firm that has its IPO on May 12, 2012 and has a December (March) 31 fiscal year.

${ }^{17}$ Although considering these groups separately provides insights into the evolution in value relevance of accounting amounts, the full sample findings are not simply a weighted average of the group findings. This is because CART estimation uses all available observations. For example, NI could be more relevant in the full sample than as indicated by the separate estimations for Non-New Economy Profit and Loss firms because in the full sample NI distinguishes profit and loss firms, which is not necessary in the separate estimations. More generally, to the extent that any particular accounting amount is more highly associated with a particular type of firm, CART effectively partitions on that firm type. For example, INTAN primarily arises from acquisitions. Thus, firms with higher INTAN likely are more acquisitive. Thus, unsurprisingly, untabulated findings for acquisitive firms, i.e., firms with $\mathrm{AQC}>0$, where AQC is cash paid for acquisitions from Compustat, reveal a significant increasing trend for INTAN, similar to the full sample.
} 
We require that firms list on NYSE, NASDAQ, or AMEX and have non-missing net income, equity book value, share price, number of shares outstanding, total assets, lagged total assets, revenue, and SIC code. ${ }^{18}$ If operating cash flow from the Statement of Cash Flows is missing, we estimate it using the Sloan (1996) approach. ${ }^{19}$ We set to zero any other missing accounting amount. We winsorize all non-indicator variables at the 1st and 99th percentiles, by year, to mitigate the effect of outliers on estimation results.

Table 1 presents descriptive statistics and correlations for price and the non-indicator accounting amounts. Panel A reveal mean price, $P$ (net income, $N I$ ), is $18.89(0.90)$, which is higher (lower) than the 16.98 and 17.58 (1.10 and 1.29) in Brown et al. (1999) and Collins et al. (1997). These differences from prior research reflect an increase (decrease) in price (earnings) since the time of those studies, which is consistent with a decline in earnings' relevance.

Table 1, Panel B, presents correlations between the variables. We present Pearson correlations to facilitate comparison to prior research. CART estimation is non-parametric and, thus, any skewness in the distributions apparent from differences between Pearson and Spearman correlations has no effect on our estimations. Regarding correlations with price, equity book value has the largest, followed closely by net income. The Pearson (Spearman) correlations are $0.63(0.73)$ for equity book value and $0.61(0.72)$ for net income. Research and development expense, which we code as positive, has a positive correlation with price (Pearson and Spearman corrs. $=0.23$ and 0.03 ), which is consistent with the expense reflecting investment in technology.

\section{Findings}

\footnotetext{
${ }^{18}$ We require lagged assets to ensure prior year accounting amounts are in Compustat because several variables, such as other comprehensive income and revenue growth, require prior year amounts to compute.

${ }^{19}$ Sloan (1996) estimates accruals by taking differences in changes in current assets and current liabilities. We estimate operating cash flow as net income less estimated accruals. Although operating cash flows are missing prior to implementation of SFAS 95 in 1987, our finding that operating cash flows increase in value relevance is not solely attributable to the implementation of SFAS 95. Untabulated findings reveal that operating cash flows increase in value relevance from 1989 to 2014 (t-stat. $=7.12$ ).
} 


\subsection{Value relevance over time}

Table 2 presents findings relating to combined value relevance. Table 2 reveals mean OOS R $\mathrm{R}^{2}$ is $69.8 \%$ from 1962 to 2014 . More importantly, Table 2 reveals OOS R ${ }^{2}$ increases at a rate of 0.238 percentage points per year $(\mathrm{t}$-stat. $=3.25)$, which is inconsistent with a decline in value relevance of accounting amounts.

Table 2 also reveals combined value relevance fluctuates across decades, but there is no systematic decline. In particular, in the 1960 s combined value relevance is $57.7 \%$ with no significant within-decade trend $(\mathrm{t}-\mathrm{stat} .=-0.40)$. In the 1970s it increases to $67.2 \%$, with a significant positive within-decade trend $(\mathrm{t}-\mathrm{stat}=2.84)$. In the $1980 \mathrm{~s}$ and $1990 \mathrm{~s}$, it increases to $78.2 \%$ and then decreases to $70.5 \%$; the within-decade the trends are significantly positive and negative (t-stats. $=3.41$ and -3.79$)$. Lower relevance in the $1990 \mathrm{~s}$ and a declining within-decade trend are consistent with investors trading away from fundamentals at the height of the technology bubble (see footnote 3). They also can explain why prior research using sample periods ending near the end of the 1990s finds a declining trend in combined value relevance (e.g., Brown et al. 1999). In the 2000s and 2010s, combined value relevance is $71.7 \%$ and $72.3 \%$, with an insignificant within-decade trend (t-stats. $=1.38$ and 1.74). Thus, the relevance of accounting information is not significantly lower in the 2000s and 2010s than in the 1960s and 1970s. ${ }^{20}$ Taken together, the findings in Table 2 are consistent with our expectation of no significant decline in the relevance of accounting information.

\subsection{Value relevance of individual accounting amounts}

\footnotetext{
${ }^{20}$ As section 2.2 explains, the accounting amounts are those available for the entire sample period. Yet, prior research finds more recently available accounting amounts are value relevant, such as share repurchases and issuances, total assets and total liabilities at fair value, stock-based compensation expense, and several pension amounts (Barth et al. 2001; Aboody, Barth, and Kasznik 2004; Hribar, Jenkins, and Johnson 2006). Untabulated findings from estimating Equation (1) for 2014 reveal the CART OOS $\mathrm{R}^{2}$ is $74.5 \%(72.6 \%)$ with these variables included (excluded), which suggests our combined value relevance estimates are lower than they would be if we included more accounting amounts.
} 
Figure 1 shows the evolution in value relevance, $V R$, of the accounting amounts, which largely are consistent with our expectations. First, Figure 1 reveals the decline (increase) in relevance of $N I(B V E)$. Second, it reveals an increase in number of relevant accounting amounts, particularly those related to intangible assets, growth opportunities, and alternative performance measures, which were barely noticeable in the 1960s. The pie charts display the accounting amounts with the largest $V R$, in clockwise order, needed explain $90 \%$ of combined value relevance (hereafter, important amounts). The pie charts reveal a stark contrast between the 1960s and 2010s. In the 1960s, the relevance of $N I$ dominated that of other accounting amounts, and there are only five important amounts, none of which relates to intangible assets, growth opportunities, or alternative performance measures. In the 2010s, NI is considerably less dominant, and there are nine other important amounts, five of which relate to intangible assets, growth opportunities, and alternative performance measures.

The sharp decline in earnings' relevance in the late 1990s and early 2000s largely is associated with the technology bubble. ${ }^{21}$ Untabulated statistics reveal that in 1999 , the year of lowest relevance of earnings, cash and revenue growth are among the three most important accounting amounts. This finding reveals growth opportunities were highly relevant at the height of the technology bubble. Figure 1 reveals that subsequently the relevance of earnings increases (Balachandran and Mohanram 2011).

Table 3 presents statistics underlying Figure 1. The first column in Panel A presents mean value relevance for each accounting amount across all years. It reveals net income, $N I$, is the most relevant accounting amount. NI's mean $V R$ of $46.1 \%$ indicates it provides nearly half of the

\footnotetext{
${ }^{21}$ Figure 1 and untabulated findings reveal the two years for which the industry indicators have the highest $V R$ are 1979, the year of the second oil crisis, and 1999, the height of the technology bubble. Also, untabulated findings reveal in 1979 (1999) Fama-French industry 4, oil and gas, (industries 5 and 6, high technology and telecommunication) is the (are the two) most value relevant industry indicator(s). See also footnote 3.
} 
combined value relevance of the accounting amounts. However, consistent with the declining trend in relevance of $N I$, Panel A also reveals this proportion declines almost steadily from $62.1 \%$ in the 1960 s to $32.8 \%$ in the 2010 s. The only decade with an increase is the 2000 s, which reflects some recovery after the technology bubble. Panel A also reveals equity book value, $B V E$, is the second most relevant accounting amount across all years (mean $V R=17.2 \%$ ). However, its value relevance increases noticeably in the 1980 s, from $6.6 \%$ to $21.8 \%{ }^{22}$ and remains about the same after that, except for the 2010 s when it declined from $24.9 \%$ to $19.1 \%$. Operating cash flow, $C F$, exhibits the largest increase in relevance in recent years-from $2.5 \%$ in the 1990 s, to $6.7 \%$ in the 2000 s, to $10.9 \%$ in the 2010 s.

Table 3, Panel B, presents estimates of $\beta_{1}$ from Equation (3). As expected, Panel B reveals the relevance of $N I(B V E)$ significantly declines (increases) (t-stats. $=-9.91$ and 5.68). Also as expected, Panel B reveals accounting amounts related to intangible assets, growth opportunities, and alternative performance measures become more relevant. In particular, $R D$, INTAN, CASH, REVGR, CF, REV, and SPI all significantly increase in relevance (t-stats. range from 2.46 to 9.51$)$. Only $A D V$ and $O C I$ exhibit insignificant trends $(\mathrm{t}$-stats. $=-0.08$ and -0.26$) .^{23}$ Consistent with these individual amounts' trends, the statistics related to trends in combined relevance for accounting amounts related to intangible assets, Intans, growth opportunities,

\footnotetext{
${ }^{22}$ Untabulated statistics reveal this increase in $B V E$ 's relevance largely occurred in the early 1980s. Economy-wide earnings were lower during the 1981 and 1982 recession, which likely resulted in increased relevance of $B V E$ (Barth et al. 1998a; Collins et al. 1999). Also, the proportion of Non-New Economy Loss firms increased and, as Figure 2, Panel C, reveals, $B V E$ is by far the most relevant accounting amount for these firms. Another possible explanation is changes in accounting standards. From 1980 to 1983 approximately forty Statements of Financial Accounting Standards (SFAS) became effective. However, there was no single, or even a few, major standards. Rather, most new SFASs incorporated into FASB literature prior industry-specific AICPA guidance. Regardless, the large number of standards precludes us from isolating their effects from other changes in the economy.

${ }^{23}$ Our finding $O C I$ is value relevant throughout our sample period might seem in contrast to Chambers, Linsmeier, and Shakespeare (2007), which finds value relevance for a sample of S\&P 500 firms only from 1997 to 2003 after OCI became required disclosure. As-reported OCI must be hand-collected, which is infeasible for our larger sample, and is not available for our entire sample period. Thus, we define $O C I$ using the Dhaliwal, Subramanyam, and Trezevant (1999) as-if approach. Based on Chambers et al. (2007), using as-reported OCI should increase the relevance of OCI, which would strengthen our inference that the value relevance of accounting has not declined.
} 
Growth, and alternative performance measures, AltPerf, reveal each category significantly increases in relevance (t-stats. $=3.59,4.02$, and 12.32). Regarding the other accounting amounts, Panel B reveals, as expected, a significant decline in DIV's relevance $(\mathrm{t}$-stat. $=-4.24) .{ }^{24}$ Although we have no predictions, Panel B also reveals that $C A P X$ 's and $S G A$ 's relevance significantly increases (t-stats. $=2.44$ and 1.83), and COGS's and ASSETS's significantly decline (t-stats. $=-3.91$ and -2.85$)$.

Table 3, Panel C, presents estimates of $\beta_{1}$ from Equation (4) and reveals a significant increase in the number of important accounting amounts, regardless of threshold (t-stats. range from 6.18 to 10.03). This finding indicates that over time price reflects information in more accounting amounts, which reveals a more nuanced relation between the amounts and price.

\subsection{Value relevance of accounting amounts for new economy and non-new economy firms}

Table 4 presents descriptive statistics for New Economy, Non-New Economy Profit, and Non-New Economy Loss firms, which comprise 73,690, 120,568, and 23,466 observations from 1971 to 2014 (untabulated). Panel A presents the proportion of firms comprising each group and Panel B presents distributional statistics, by group, for the variables we use. Panel A reveals that New Economy, Non-New Economy Profit, and Non-New Economy Loss firms comprise, on average, $30.8 \%, 58.9 \%$, and $10.3 \%$ of the observations. As expected, Panel A reveals that the proportion of New Economy firms increases significantly from $11.1 \%$ in the 1970 s to $38.0 \%$ in the 2010s at an annual rate of 0.750 percentage points ( $\mathrm{t}$-stat. $=10.84$ ), and the proportion of Non-New Economy Profit firms significantly decreases from $82.5 \%$ to $51.3 \%$ at a somewhat higher an annual rate of -0.855 percentage points $(\mathrm{t}-\mathrm{stat} .=-9.04)$. The proportion of Non-New

\footnotetext{
${ }^{24}$ More recently, firms repurchase shares as a substitute for dividends, but share repurchases data are available only from 1971. Untabulated findings based on including share repurchases in Equation (1) from 1971 to 2014 reveal a significantly positive relevance trend in that its Equation (3) coefficient is 0.028 (t-stat. $=5.56)$.
} 
Economy Loss firms also increases significantly but only from $6.5 \%$ to $10.6 \%$, which is an annual rate of only 0.106 percentage points $(\mathrm{t}$-stat. $=2.74)$. Not surprisingly, Panel B reveals mean $N I$ is small for New Economy firms, negative for Non-New Economy Loss firms, and positive for Non-New Economy Profit firms (mean values of 0.04, -1.34 , and 1.79).

Figure 2 shows the evolution in value relevance, $V R$, of each accounting amount for the three groups of firms that largely are consistent with our expectations and reveal the changes in relevance are not limited to New Economy firms. Untabulated findings reveal that the mean combined OOS R²s from 1971 to 2014 for New Economy, Non-New-Economy Profit, and NonNew Economy Loss firms are 69.4\%, 68.0\%, and 50.0\%. As expected, each is lower than $72.1 \%$ for the full sample over the same period (see footnote 17). Regarding New Economy firms, Panel A shows a steep decline in relevance of $N I$ and a large increase in relevance of other accounting amounts. As with the full sample in Figure 1, the pie charts reveal that in the 1970s the relevance of $N I$ dominated that of the four other important accounting amounts. Unlike the full sample, one of these, $R D$, relates to intangible assets. In the 2010s there are nine important accounting amounts, five of which relate to intangible assets, growth opportunities, and alternative performance measures.

Regarding Non-New Economy Profit firms, Panel B also shows a decline in NI's relevance, although — as expected — it is not as pronounced as it is for New Economy firms. However, as with New Economy firms, amounts related to growth opportunities and alternative performance measures are barely noticeable in the 1970s, but explain a large portion of equity value in the 2010s. As in Panel A, the pie charts reveal that in the 1970s NI's relevance is dominant, and $R E V$ is among the five other important amounts. In the 2010s $N I$ is less dominant, 
and of the eight other important amounts, three relate to intangible assets, growth opportunities, and alternative performance measures.

Regarding Non-New Economy Loss firms, Panel C shows NI has little relevance in any year. The pie charts reveal that $B V E$ is the dominant accounting amount in both the 1970 s and the 2010s. In the 1970s, there are seven additional important accounting amounts, two of which relate to growth opportunities and alternative performance measures. In the 2010 s, there are eight additional important accounting amounts, three of which relate to intangible assets, growth opportunities, and alternative performance measures. Thus, as with New Economy and NonNew Economy Profit firms, amounts related to intangible assets, growth opportunities, and alternative performance measures were almost unnoticeable in the 1970s, but are noticeable by the 2010s. NI is not important in either decade.

Table 5 presents statistics underlying Figure 2. Table 5, Panel A, reveals that NI has the highest mean value relevance across all years for New Economy and Non-New Economy Profit firms, $45.4 \%$ and $49.5 \%$. However, although it has declined for both groups of firms, as expected, the decline is more dramatic for New Economy firms - from 71.4\% in the 1970s to only $23.8 \%$ in the 2010 s for New Economy firms and from $55.6 \%$ to $45.0 \%$ for Non-New Economy Profit firms. For Non-New Economy Loss firms, $B V E$ consistently has the highest mean value relevance, $51.4 \%$ across all years, $48.9 \%$ in the 1970 s, and $53.7 \%$ in the $2010 \mathrm{~s}$. NI has little relevance for these firms - across all years, in the 1970s, and in the 2010s, mean value relevance was only $0.6 \%, 0.7 \%$, and $0.6 \%$. The increasing proportion of New Economy and Non-New Economy Loss firms reported in Table 4, Panel A, and the low relevance of NI for these firms help explain the decline in relevance of $N I$ in Table 3. 
Regarding other accounting amounts, across all years, Table 5, Panel A, reveals intangible assets are more relevant for New Economy firms than for Non-New Economy firms, as expected. Mean $V R$ for Intans is $6.3 \%$ for New Economy firms and 3.6\% (4.2\%) for Non-New Economy Profit (Loss) firms. By the 2010s, growth and alternative performance measures, as expected, are more relevant for New Economy firms (14.6\% and 25.9\%) than for Non-New Economy firms (3.7\% and $15.8 \%$ for Profit; $4.4 \%$ and $8.9 \%$ for Loss). By contrast, DIV is less relevant for New Economy firms than for Non-New Economy firms (1.8\% versus 5.2\% for Profit and 7.7\% for Loss). The increasing proportion of New Economy firms reported in Table 4, Panel A, and the high (low) relevance of Intans, Growth, and AltPerf (DIV) for these firms contribute to the increase (decline) in relevance for these accounting amounts in Table 3.

Table 5, Panel B, presents estimates of $\beta_{1}$ from Equation (3) that largely are consistent with our expectations. Panel B reveals NI exhibits a significant relevance decline for New Economy firms, which is substantially larger than the decline for Non-New Economy Profit firms (trends $=-1.227$ and $-0.252 ;$ t-stats. $=-8.73$ and -2.86 ). Although $N I$ exhibits no significant decline in relevance for Non-New Economy Loss firms (trend $=-0.000$; t-stat. $=-$ 0.01), recall from Panel A that earnings has little relevance for these firms. $B V E$ exhibits a significant increase in relevance for New Economy firms, which is somewhat larger than the increase for Non-New Economy Profit firms (trends $=0.290$ and 0.207; t-stats. $=2.97$ and 2.60). $B V E$ exhibits no significant relevance change for Non-New Economy Loss firms (trend =0.017 ; t-stat. $=-0.10$ ), but remains the most relevant amount for these firms.

Panel B also reveals accounting amounts related to growth opportunities- $\mathrm{CASH}$ and $R E V G R$ - and alternative performance measures - $C F$ and $R E V$ - have substantially more 
positive trends for New Economy firms than for Non-New Economy firms. ${ }^{25}$ Unexpectedly, but consistent with economy-wide changes, trends in amounts related to intangible assets for New Economy firms are not notably different from those for other firms.

Panel B reveals significant increases in relevance for INTAN and $C F$ for all three groups of firms. It also reveals that relevance of amounts related to growth opportunities and alternative performance measures significantly increase for all groups (t-stats. range from 3.27 to 9.26), except for amounts related to growth opportunities for Non-New Economy Loss firms, which also increases, but not significantly so $(\mathrm{t}$-stat. $=1.58)$. These findings suggest firms emblematic of the new economy are not solely responsible for the increases in relevance of these accounting amounts. Rather, the increases extend beyond new economy firms.

The findings in Table 5 reveal that, as expected, the value relevance of accounting amounts differs markedly for profit and loss firms. Because New Economy firms can report profits or losses, we consider separately the 34,925 (38,765) New Economy profit (loss) observations to provide insights into the extent to which the New Economy findings are driven by one or the other (untabulated). ${ }^{26}$

Figure 3, Panel A (B) presents the evolution in value relevance of accounting amounts for New Economy Profit (Loss) firms. As expected, Panel A reveals patterns somewhat less (considerably more) pronounced than those in Figure 2, Panel A (B), which is based on all New Economy (Non-New Economy Profit) firms. Strikingly, Figure 3, Panel B, which is based on New Economy Loss firms, bears less resemblance to Figure 2, Panel C, which is based on NonNew Economy Loss firms, except for the very low value relevance of $N I$, and more resemblance

\footnotetext{
${ }^{25} R D$ does not exhibit an increasing trend for New Economy firms, which could be because $R D$ is more value relevant for these firms throughout the sample period leaving less scope for a significant increase. The average value relevance of $R D$ is $5.4 \%$ for New Economy firms and $3.0 \%$ for the full sample.

${ }^{26}$ Of the 38,765 loss observations, 6,999 relate to the IPO-year loss (untabulated).
} 
to New Economy Profit firms. In fact, untabulated statistics reveal that the sums of the value relevance of individual accounting amounts relating to Intans, Growth, and AltPerf in the 2010s for New Economy (Non-New Economy) Loss and Profit firms are 59.3\% and 43.1\% (17.9\% and $23.5 \%)$.

\section{Additional analyses}

\subsection{Constant sample}

We base our main findings on samples that change composition over time. We do this because we are interested in how value relevance evolves as the economy evolves, which includes entrance and exit of firms with potentially different business models. However, using a changing sample precludes us from identifying how relevance of accounting information evolved for the same set of firms. Thus, we estimate value relevance for the 340 firms that survive from 1971 to 2014. A disadvantage to using this constant sample is that requiring firms to exist for so many years affects the extent to which our findings apply more generally because such firms had sustained, profitable performance. Regardless, the most notable untabulated statistics indicate earnings is the most relevant accounting amount (mean $V R=60.8 \%$ ) and its relevance does not decline (t-stat. $=1.00)$. In addition, although relevance of amounts related to alternative performance measures increases significantly $(\mathrm{t}$-stat. $=4.17)$, those related to intangible assets and growth opportunities do not (t-stats. $=-0.54$ and -0.60$)$, which is unsurprising for these long-established firms.

\subsection{Scale effects}

As explained in section 3.1, we estimate Equation (1) using share-deflated variables to facilitate comparison with prior research examining trends in value relevance of accounting information. However, Brown et al. (1999) expresses concern about using $\mathrm{R}^{2}$ to measure value 
relevance in the presence of scale effects. Brown et al. (1999) assumes a multiplicative scale effect and recommends scaling all variables, except industry indicators, by beginning-of-year price. More recently, Barth and Clinch (2009) finds deflation by shares generally is effective in mitigating a variety of scale effects, including multiplicative, in regressions similar to Equation (1), but deflating by beginning-of-year price is not. In addition, deflating by beginning-of-year price effectively transforms the dependent variable from price to return. Gu (2005) shows the Brown et al. (1999) inferences relating to changes in $\mathrm{R}^{2}$ over time are attributable to price and return models differing as to the economic relations they represent rather than to scale effects. Nonetheless, we estimate Equation (1) from 1963 to 2014 using a beginning-of-year-pricedeflated specification based on CART using all accounting amounts. Untabulated findings reveal no significant decline $(\mathrm{t}$-stat. $=0.39)$.

As an alternative, Brown et al. (1999) recommends including in Equation (2) the crosssectional coefficients of variation of equity book value and price. We are reluctant to rely on inferences from this approach because including the coefficient of variation of equity book value as an explanatory variable likely removes the effect we seek to test. ${ }^{27}$ Regardless, untabulated findings based on implementing this approach using CART and all accounting amounts reveal no significant decline in combined value relevance $(\mathrm{t}$-stat. $=0.68)$.

\section{Conclusion}

\footnotetext{
${ }^{27}$ The intuition is as follows. Assume price is a linear function of equity book value and random noise. The $\mathrm{R}^{2}$ of a regression of price on equity book value would increase in the variance of equity book value. Thus, if this variance increases because equity book value conveys more information about price and nothing else changes, $\mathrm{R}^{2}$ would increase. However, this also would result in equity book value's coefficient of variation being a significant explanatory variable in Equation (2) because its numerator (denominator) increases (remains constant). It also would not be surprising if the time trend coefficient were insignificantly different from zero incremental to this variable, even though the increase in equity book value's coefficient of variation is attributable to the increase in equity book value's value relevance. We thank Greg Clinch for insights into this analysis.
} 
The question we address is how the value relevance of accounting information has evolved as the economy transitioned from primarily industrial to a new economy based on services and information technology. Prior research concludes the value relevance of accounting information - particularly earnings — has declined, and largely attributes the decline to the shift to the new economy.

We assess value relevance by determining the power of accounting amounts to explain equity price. In addition to earnings and equity book value, we consider accounting amounts that reflect information about intangible assets, growth opportunities, and alternative performance measures, all of which we expect are more relevant in the new economy, as well as dividends, capital expenditures, COGS, SGA, total assets, and ten industry indicators. Prior research predicts and finds these amounts are value relevant incremental to earnings. However, not all of the amounts are included in prior research studying trends in value relevance of accounting information.

We base our inferences on estimating the relation between price and accounting amounts using Classification and Regression Trees (CART), which automatically incorporates nonlinearities and interactions that minimize out-of-sample prediction errors. We estimate annual relations from 1962 to 2014 and use out-of-sample explanatory power as the value relevance metric. We show CART avoids overstating value relevance that can occur when using OLS estimation and avoids understating value relevance because its flexible approach enables the underlying relevance of the accounting amounts to manifest more fully.

In contrast to prior research, we find no decline in combined value relevance of accounting information. If anything, we find some evidence of an increase. Consistent with prior research, we find earnings (equity book value) has become significantly less (more) 
relevant. More importantly for our research question, we find accounting amounts related to intangible assets, growth opportunities, and alternative performance measures become significantly more relevant. Although we find these trends are most pronounced for firms emblematic of the new economy, they also extend beyond new economy firms, which indicates that new economy firms are not solely responsible for the relevance increases. We also find more accounting amounts have become relevant, which reveals the relation between price and accounting amounts has become more nuanced.

Our findings provide insights into how accounting information reflects information investors use in valuing firms in the new economy. The increasing relevance of accounting amounts related to intangible assets, growth opportunities, and alternative performance measures reveals these categories of information are relevant to investors in the new economy, despite their incomplete reflection in accounting. This, in turn, suggests enhancing their reflection in accounting, for example, by improving accounting for intangible assets, ensuring financial statements include key inputs to investors' assessments of growth opportunities, and relaxing the emphasis on a single performance measure, could increase the relevance of accounting information. Our findings also provide insights potentially relevant to equity valuation. In particular, our findings suggest an increasing number of accounting amounts, most notably those related to intangible assets, growth opportunities, and alternative performance measures, reflect information relevant to valuing firms. This trend is also not solely limited to firms emblematic of the new economy.

Taken together, our findings reveal an evolution in value relevance of accounting information beyond earnings and equity book value to a more nuanced relation between accounting amounts and share price that reflects the rise in the new economy, not a declining 
relation. Thus, our findings indicate it is premature to conclude accounting information has lost its relevance. 


\section{References}

Aboody, D. M.E. Barth, and R. Kasznik. 2004. SFAS No. 123 stock-based compensation expense and equity market values. The Accounting Review 79: 251-275.

Aboody, D., and B. Lev. 1998. The value relevance of intangibles: The case of software capitalization. Journal of Accounting Research 36 (Supplement): 161-191.

Balachandran, S., and P. Mohanram. 2011. Is the decline in value relevance of accounting driven by increased conservatism? Review of Accounting Studies 16: 272-301.

Barth, M.E., Beaver, W.H., Hand, J.R.M., and W.R. Landsman. 1999. Accruals, cash flows, and equity values. Review of Accounting Studies 3: 205-229.

Barth, M.E., Beaver, W.H., and W.R. Landsman. 1998a. Relative valuation roles of equity book value and net income as a function of financial health. Journal of Accounting and Economics 25: 1-34.

Barth, M.E., Beaver, W.H., and W.R. Landsman. 2001. The relevance of the value relevance literature for financial accounting standard setting: Another view. Journal of Accounting and Economics 31: 77-104.

Barth, M.E., Clement, M.B., Foster, G., and R. Kasznik. 1998b. Brand values and capital market valuation. Review of Accounting Studies 3: 41-68.

Barth, M.E., and G. Clinch. 2009. Scale effects in capital markets-based accounting research. Journal of Business Finance \& Accounting 36(3\&4): 253-288.

Barth, M.E., Konchitchki, Y., and W.R. Landsman. 2013. Cost of capital and earnings transparency. Journal of Accounting and Economics 55: 206-224.

Beaver, W. H., Cascino, S., Correia, M., and M. F. McNichols. 2018. Group Affiliation and Default Prediction. Forthcoming, Management Science.

Bhattacharya, N., Black, E. L., Christensen, T. E., and Larson, C. R. 2003. Assessing the relative informativeness and permanence of pro forma earnings and GAAP operating earnings. Journal of Accounting and Economics 36(1): 285-319.

Bradshaw, M. T., and Sloan, R. G. 2002. GAAP versus the street: An empirical assessment of two alternative definitions of earnings. Journal of Accounting Research 40(1): 41-66.

Breiman, L. 2001. Random Forests. Machine Learning 45(1): 5-32. 
Brown, S., Lo, K., and T. Lys. 1999. Use of $\mathrm{R}^{2}$ in accounting research: Measuring changes in value relevance over the last four decades. Journal of Accounting and Economics 28: 83115.

Brunnermeier, K., and S. Nagel. 2004. Hedge funds and the technology bubble. Journal of Finance 59(5): 2013-2040.

Buera, F.J., and J.P. Kaboski. 2012. The rise of the service economy. American Economic Review 102(6): 2540-2569.

Callen, J.L., Robb, S.W.G., and D. Segal. 2008. Revenue manipulation and restatements by loss firms. Auditing: A Journal of Practice and Theory 27(2): 1-29.

Chambers, D., Linsmeier, T. J., Shakespeare, C., and T. Sougiannis. 2007. An evaluation of SFAS No. 130 comprehensive income disclosure. Review of Accounting Studies 12(4): 557593.

Collins, D.W., Maydew, E. L., and I. S. Weiss. 1997. Changes in the value-relevance of earnings and book values over the past forty years. Journal of Accounting and Economics 24: 39-67.

Collins, D. W., Pincus, M., and H. Xie. 1999. Equity valuation and negative earnings: The role of book value of equity. The Accounting Review 74(1): 29-61.

Core, J. E., Guay, W. R., and A. Van Buskirk. 2003. Market valuations in the New Economy: An investigation of what has changed. Journal of Accounting and Economics 34: 43-67.

Correia, M., Kang, J., and S. Richardson. 2017. Asset Volatility. Available at: https://papers.ssrn.com/sol3/papers.cfm?abstract_id=2361686.

Damodaran, A. 2009. Valuing financial services firms. Retrieved January 2, 2016 from http://people.stern.nyu.edu/adamodar/pdfiles/papers/finfirm09.pdf.

Darrough, M., and J. Ye. 2007. Valuation of loss firms in a knowledge-based economy. Review of Accounting Studies 12: 61-93.

Davern, M., N. Gyles, D. Hanlon, and M. Pinnuck. 2018. Is financial reporting still an effective tool for equity investors in Australia? Working paper. University of Melbourne.

Davis, A. K. 2002. The value relevance of revenue for internet firms: Does reporting grossed-up or barter revenue make a difference? Journal of Accounting Research 40(2): 445-477.

Dhaliwal, D., Subramanyam, K. R., and R. Trezevant. 1999. Is comprehensive income superior to net income as a measure of firm performance? Journal of Accounting and Economics 26: 43-67. 
Dichev, I.A., and V.W. Tang. 2008. Matching and the changing properties of accounting earnings over the last 40 years. The Accounting Review 83(6): 1425-1460.

Donelson, D. C., Jennings, R., and J. McInnis. 2011. Changes over time in the revenue-expense relation: Accounting or economics? The Accounting Review 86(3): 945-974.

Dontoh, A., Radhakrishnan, S., and J. Ronen. 2004. The declining value-relevance of accounting information and non-information-based trading: An empirical analysis. Contemporary Accounting Research 21(4): 795-812.

Ertimur, Y., Livnat, J., and M. Martikainen. 2003. Differential market reactions to revenue and expense surprises. Review of Accounting Studies 8: 185-211.

Fama, E.F., and K.R. French. 1992. The cross-section of expected returns. Journal of Finance 47(2): 427-465.

Fama, E.F., and K.R. French. 1993. Common risk factors in the returns on stocks and bonds. Journal of Financial Economics 33: 3-56.

Fama, E.F., and K.R. French. 2015. A five-factor asset pricing model. Journal of Financial Economics 116: 1-22.

Faulkender, M., and R. Wang. 2006. Corporate financial policy and the value of cash. Journal of Finance 61(4): 1957-1990.

Filip, A., A. Ghio, and L. Paugam. 2018. Accounting information in innovative Small and Medium Entities. Working paper. ESSEC Business School.

Floyd, E., Li, N., and D.J. Skinner. 2015. Payout policy through the financial crisis: The growth of repurchases and the resilience of dividends. Journal of Financial Economics 118(2): 299-316.

Francis, J., and K. Schipper. 1999. Have financial statements lost their value relevance? Journal of Accounting Research 37(2): 319-352.

Gerakos, J. J., Hahn, R., Kovrijnykh, A., and F. Zhou. 2016. Prediction versus inducement and the informational efficiency of going concern opinions. Available at https://papers.ssrn.com/sol3/papers.cfm?abstract_id=2727771.

Gu, F. 2005. Innovation, future earnings, and market efficiency. Journal of Accounting, Auditing \& Finance 20(4): 385-418.

Hastie, T., Tibshirani, R., and J. Friedman. 2001. The Elements of Statistical Learning, Springer, New York Inc., New York, NY, U.S.A. 
Hayn, C. 1995. The information content of losses. Journal of Accounting and Economics 20: 125-153.

Holthausen, R.W., and R.L. Watts. 2001. The relevance of the value relevance literature for financial accounting standard setting. Journal of Accounting and Economics 31: 3-75.

Hribar, P., N.T. Jenkins, and W.B. Johnson. 2006. Stock repurchases as an earnings management device. Journal of Accounting and Economics 41: 3-27.

Jones, S. 2017. Corporate bankruptcy prediction: a high dimensional analysis. Review of Accounting Studies 22: 1366-1422.

Jones, D.A., and K. J. Smith. 2011. Comparing the value relevance, predictive value, and persistence of other comprehensive income and special items. The Accounting Review 86(6): 2047-2073.

Joos, P., and G.A. Plesko. 2005. Valuing loss firms. The Accounting Review 80(3): 847-870.

Kumar, K.R., and G.V. Krishnan. 2008. The value-relevance of cash flows and accruals: The role of investment opportunities. The Accounting Review 83(4): 997-1040.

Lev, B., and F. Gu. 2016. The End of Accounting and the Path Forward for Investors and Managers. John Wiley \& Sons, Inc. Hoboken, NJ, USA.

Lev, B., and T. Sougiannis. 1996. The capitalization, amortization, and value-relevance of R\&D. Journal of Accounting and Economics 21: 107-138.

Lev, B. and P. Zarowin. 1999. The boundaries of financial reporting and how to extend them. Journal of Accounting Research 37(2): 353-385.

Liaw, A., and M. Wiener. 2002. Classification and regression by randomForest. $R$ News 2(3): 1822.

Linnainmaa, J. and M. Roberts. 2016. The history of the cross section of stock returns. Retrieved March 13, 2017 from

http://faculty.chicagobooth.edu/juhani.linnainmaa/HistoricalAnomalies.pdf.

Miller, M., and F. Modigliani. 1966. "Some Estimates of the Cost of Capital to the Electric Utility Industry, 1954-57.” American Economic Review 333-391.

Miller, M.H., and K. Rock. 1985. Dividend policy under asymmetric information. Journal of Finance 40(4): 1031-1051. 
Myers, S.C., and N.S. Majluf. 1984. Corporate financing and investment decisions when firms have information that investors do not have. Journal of Financial Economics 13(2): $187-$ 221.

Ohlson, J.A. 1995. Earnings, book values, and dividends in equity valuation. Contemporary Accounting Research 11(2): 661-687.

Opler, T., Pinkowitz, L., Stulz, R., and Williamson, R. 1999. The determinants and implications of corporate cash holdings. Journal of Financial Economics 52(1): 3-46.

Ou, J.A., and S.H. Penman. 1989. Financial statement analysis and the prediction of stock returns. Journal of Accounting and Economics 11: 295-329.

Palepu, K.G., and P.M. Healy. 2008. Business analysis and valuation: Using financial statements, text and cases. 4th ed. Cengage learning.

Riffe, S., and R. Thompson. 1998. The relation between stock prices and accounting information. Review of Accounting Studies 2: 325-351.

Sloan, R.G. 1996. Do stock prices fully reflect information in accruals and cash flows about future earnings? The Accounting Review 71(3): 289-315.

Srivastava, A. 2014. Why have measures of earnings quality changed over time? Journal of Accounting and Economics 57: 196-217.

Verikas, A., Gelzinis, A., and M. Bacauskiene. 2011. Mining data with random forests: A survey and results of new tests. Pattern Recognition 44(2): 330-349.

Watts, R. 1973. The information content of dividends. The Journal of Business 46(2): 191-211.

Yee, K. 2000. Opportunities knocking: residual income valuation of an adaptive firm. Journal of Accounting, Auditing \& Finance 15(3): 225-266. 


\section{APPENDIX 1: Variable Definitions}

\begin{tabular}{|c|c|}
\hline Variable & Definition (Source) \\
\hline \multicolumn{2}{|l|}{ Share price } \\
\hline$P$ & Share price three months after fiscal year-end (Compustat prcc_q) \\
\hline \multicolumn{2}{|c|}{ Accounting amounts } \\
\hline$N I$ & Earnings divided by number of shares (Compustat ib/csho) \\
\hline$B V E$ & Book value of equity per share at fiscal year-end (Compustat ceq/csho) \\
\hline$R D$ & Research and development expenses per share (Compustat xrd/csho) \\
\hline INTAN & Intangible assets per share (Compustat intan/csho) \\
\hline$A D V$ & Advertising expense per share (Compustat xad/csho) \\
\hline CASH & $\begin{array}{l}\text { Cash, including cash equivalents, and short term investments per share } \\
\text { (Compustat che/csho) }\end{array}$ \\
\hline$R E V G R$ & Revenue growth per share (Compustat (change in revt)/csho) \\
\hline$C F$ & $\begin{array}{l}\text { Operating cash flow from the Statement of Cash Flows per share (Compustat } \\
\text { oancf/csho). If missing, we estimate this as earnings less accruals, where } \\
\text { accruals is defined as (change in current assets (act) less change in cash (che)) } \\
\text { less (change in current liabilities (lct) less change in short term debt (dlc) less } \\
\text { change in income taxes payable (txp)), scaled by number of shares, consistent }\end{array}$ \\
\hline$R E V$ & Revenue per share (Compustat revt/csho) \\
\hline$S P I$ & Special items per share (Compustat spi/csho) \\
\hline$O C I$ & $\begin{array}{l}\text { Other comprehensive income per share, calculated as retained earnings (re) } \\
\text { less lagged retained earnings plus dividends (dvc) less earnings (ib), scaled by } \\
\text { shares (csho) (Dhaliwal, Subramanyam, and Trezevant, 1999) (Compustat) }\end{array}$ \\
\hline$D I V$ & Dividends declared per share (Compustat dvc/csho) \\
\hline$C A P X$ & Capital expenditure per share (Compustat capx/csho) \\
\hline$C O G S$ & Cost of goods sold per share (Compustat cogs/csho) \\
\hline$S G A$ & Selling, general, and administrative expense per share (Compustat xsga/csho) \\
\hline ASSETS & Assets per share (Compustat at/csho) \\
\hline \multicolumn{2}{|l|}{ Industries } \\
\hline$I N D$ & Fama-French 10 industries membership (CRSP/Kenneth French Data Library) \\
\hline \multicolumn{2}{|l|}{ Other } \\
\hline$V R$ & $\begin{array}{l}\text { Variable relevance of an individual accounting amount. } \\
\text { Refer to Appendix } 2 .\end{array}$ \\
\hline$L O S S$ & $\begin{array}{l}\text { Indicator variable equal to } 1(0) \text { if the firm has negative net income } \\
\text { (otherwise) }\end{array}$ \\
\hline NUMVR & $\begin{array}{l}\text { The number of accounting amounts required to explain at least } 50 \text { percent, } 75 \\
\text { percent, } 80 \text { percent, } 90 \text { percent, or } 95 \text { percent of combined value relevance. }\end{array}$ \\
\hline OOSR2 & $\begin{array}{l}\text { Out-of-sample } \mathrm{R}^{2} \text {, estimated using ten-fold cross-validation for OLS based } \\
\text { models and out-of-bag estimates for CARTs. Refer to Appendix } 2 \text {. }\end{array}$ \\
\hline$Y E A R$ & Fiscal year (Compustat fyear) \\
\hline
\end{tabular}




\section{APPENDIX 2: Classification and Regression Trees (CART) Estimation}

This appendix describes the classification and regression trees (CART) method we use to estimate the relation between share price and accounting amounts. For more details, see Brieman (2001), Hastie et al. (2001), and Liaw and Wiener (2002).

\section{A.1 CART estimation process}

To illustrate CART estimation and how CART identifies interactions and nonlinearities, assume a data set with six observations of net income, $N I$, equity book value, $B V E$, and share price, $P$ :

\begin{tabular}{|c|c|c|c|}
\hline Observation \# & $N I$ & $B V E$ & $P$ \\
\hline 1 & 1 & 1 & 1 \\
\hline 2 & 2 & 1 & 2 \\
\hline 3 & 3 & 1 & 3 \\
\hline 4 & 1 & 2 & 11 \\
\hline 5 & 2 & 2 & 12 \\
\hline 6 & 3 & 2 & 16 \\
\hline
\end{tabular}

These data reveal a positive relation between $P$ and $B V E$, and the relation between $P$ and $N I$ is linear when $B V E=1$, but is nonlinear when $B V E=2$.

CART segments explanatory variables into regions, which is akin to developing a decision tree. CART begins with a region that contains all observations and predicts price for each observation is the average price. The two boxes below display the six observations and the initial predicted price of 7.5 for all values of $N I$ and $B V E$.
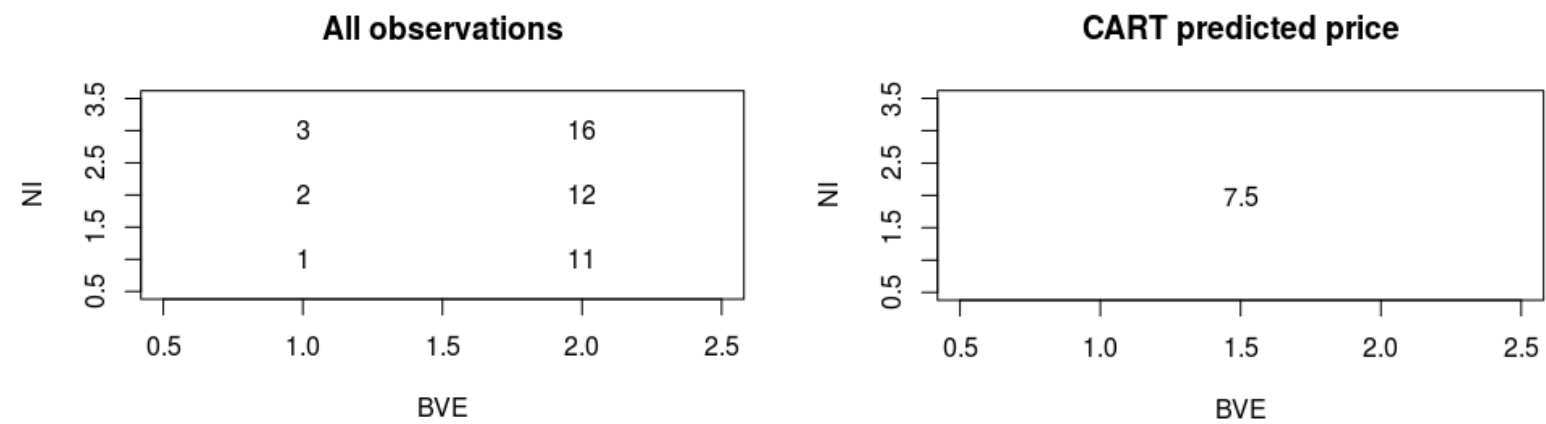

The resulting residual sum of squares is

$$
(1-7.5)^{2}+(2-7.5)^{2}+(3-7.5)^{2}+(11-7.5)^{2}+(12-7.5)^{2}+(16-7.5)^{2}=197.5
$$

CART then creates two sub-regions by splitting the initial region based on a value of one explanatory variable. After the split, the predicted price in each sub-region is the average price in that sub-region. CART searches over all possible values of $N I$ and $B V E$, and selects the split that provides the largest reduction in residual sum of squares. In the example, CART splits observations on $B V E$, specifically $B V E=1$ and $B V E=2$. This selection results in the first (second) region containing the first (remaining) three observations. 
Predicted prices in each region are the average prices in the region, which are 2 and 13.

First split

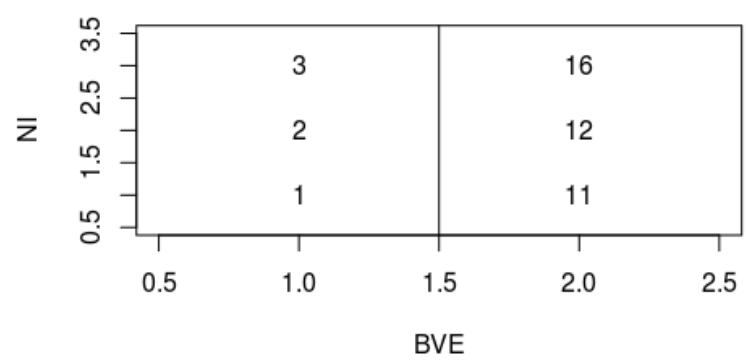

CART predicted price

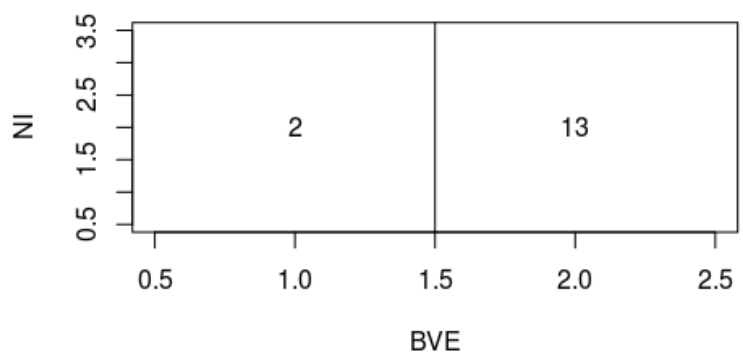

The residual sum of squares is

$$
(1-2)^{2}+(2-2)^{2}+(3-2)^{2}+(11-13)^{2}+(12-13)^{2}+(16-13)^{2}=16 .
$$

The reduction in residual sum of squares is $197.5-16=181.5$. CART selects this split because it results in the largest reduction in residual sum of squares among all possible split values on $B V E$ or $N I$.

CART further splits sub-regions into smaller sub-regions, based on minimizing the residual sum of squares. Thus, CART next splits on NI. Observations with $N I=4$ and 5 are in one sub-region and those with $N I=6$ are in another.
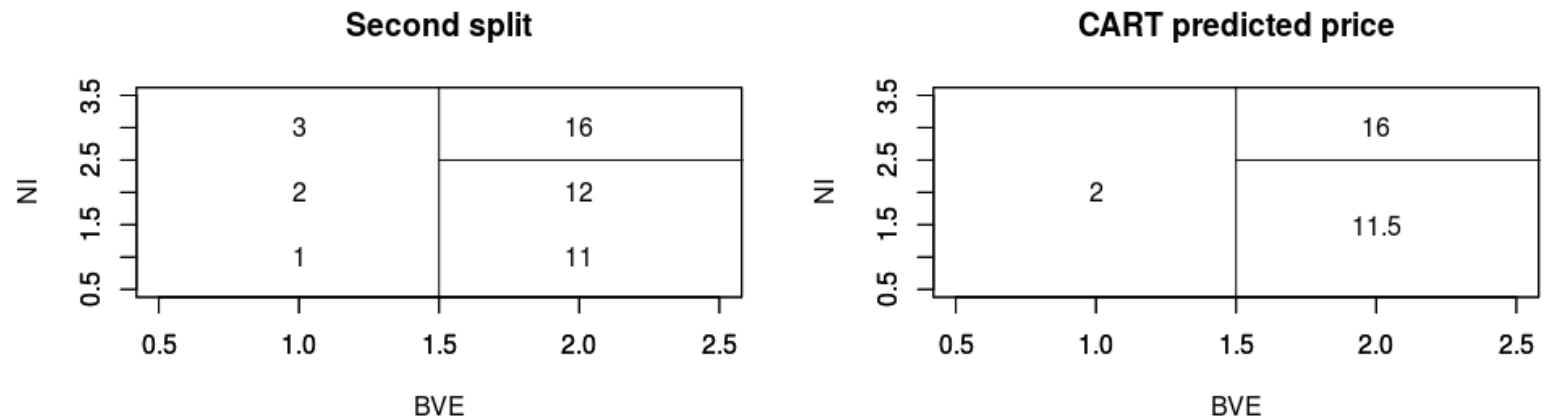

CART does three more splits, which results in one region for each observation.

Final split

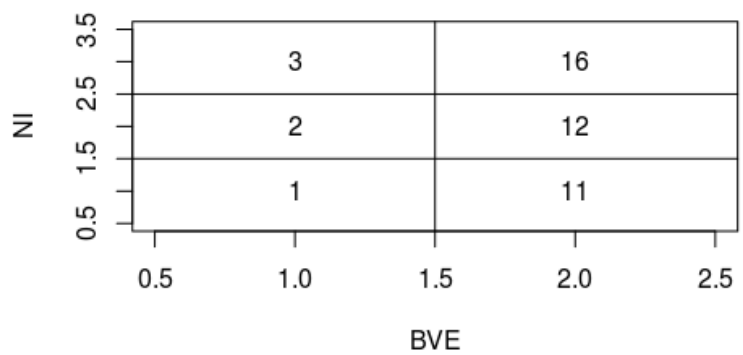

CART predicted price

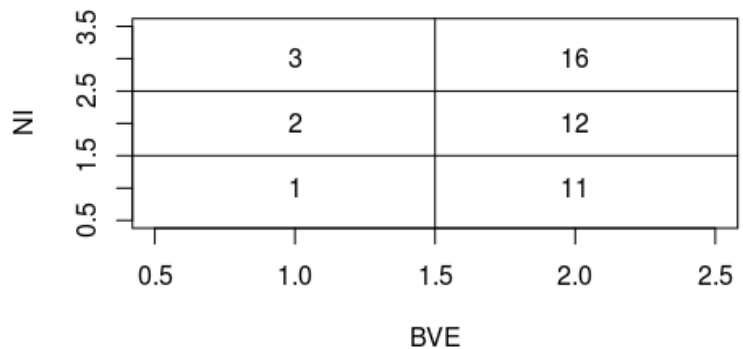


With these remaining splits, CART captures nonlinearities in the relation between $P$ and $N I$ when $B V E=2$. It also captures the interaction between $B V E$ and $N I$ because when $B V E=1$ the CART predicted price is linear in $N I$, and when $B V E=2$ it is nonlinear. Although not apparent in this example, CART can re-use variables for splits after using other variables. For example, CART splitting first by $B V E$ and then by $N I$ does not preclude using $B V E$ to identify subsequent splits.

To implement CART, we follow Hastie et al. (2001). First, we require at least five observations in each sub-region. Second, we bootstrap the data 500 times, drawing bootstrapped samples with the same sample size as the actual sample. Each time, we draw from the actual sample with replacement, which creates bootstrapped samples with, on average, 63.2 percent of unique observations (Hastie et al. 2001). We then generate a decision tree for each bootstrapped sample. Predicted price is the average of the predicted prices from these 500 decision trees.

Figure A2.1 provides an example of one decision tree. For this example, we use all 2014 observations and allow a maximum of four splits. ${ }^{28}$ The figure reveals that the first split is on NI, with a split amount of 2.687. Observations with $N I$ less than 2.687 are further split by whether $C F$, operating cash flow, is greater than or equal to 1.894 , and observations with $N I$ greater than or equal to 2.687 are further split by whether $N I$ is greater than or equal to 6.734 . This process continues until the final predictions for prices are determined, which are presented at the bottom of the figure.

The example shows that a firm with $N I<2.687, C F<1.894, R D<2.983$, and $B V E<4.306$ has a predicted share price of $\$ 7.787$, which is the lowest predicted price. These firms are less profitable, as measured by $N I$ and $C F$, and have fewer growth opportunities, as measured by low $R D$ and $C A S H$, which may justify the low price. In contrast, the example shows that a firm with $N I>=6.734, C F>=9.028$, and $I N T A N>=13.12$ has a predicted share price of $\$ 174.20$, which is the highest predicted price. These firms are the most profitable, as measured by NI and $C F$, and have large recognized intangible assets which may justify the high price.

The value relevance of an individual accounting amount, $V R$, is the increase in mean squared price prediction error of the out-of-bag observations, averaged over all bootstrapped samples, when CART randomly assigns the accounting amount. ${ }^{29}$ An observation is out-of-bag when it is not included in a bootstrapped draw. We scale $V R$ by the sum of the increases in mean squared price prediction error for all the accounting amounts.

\footnotetext{
${ }^{28}$ In the CART estimation we use in our tests, we do not impose the four-split maximum; we impose it here to produce a figure that can be displayed on one page. The unconstrained number of splits for these data used in the figure is 24 (untabulated).

${ }^{29} V R$ for the industry indicators is the sum of increase in prediction error of randomly assigning each individual industry.
} 
FIGURE A2.1: Example of CART with 2014 Data

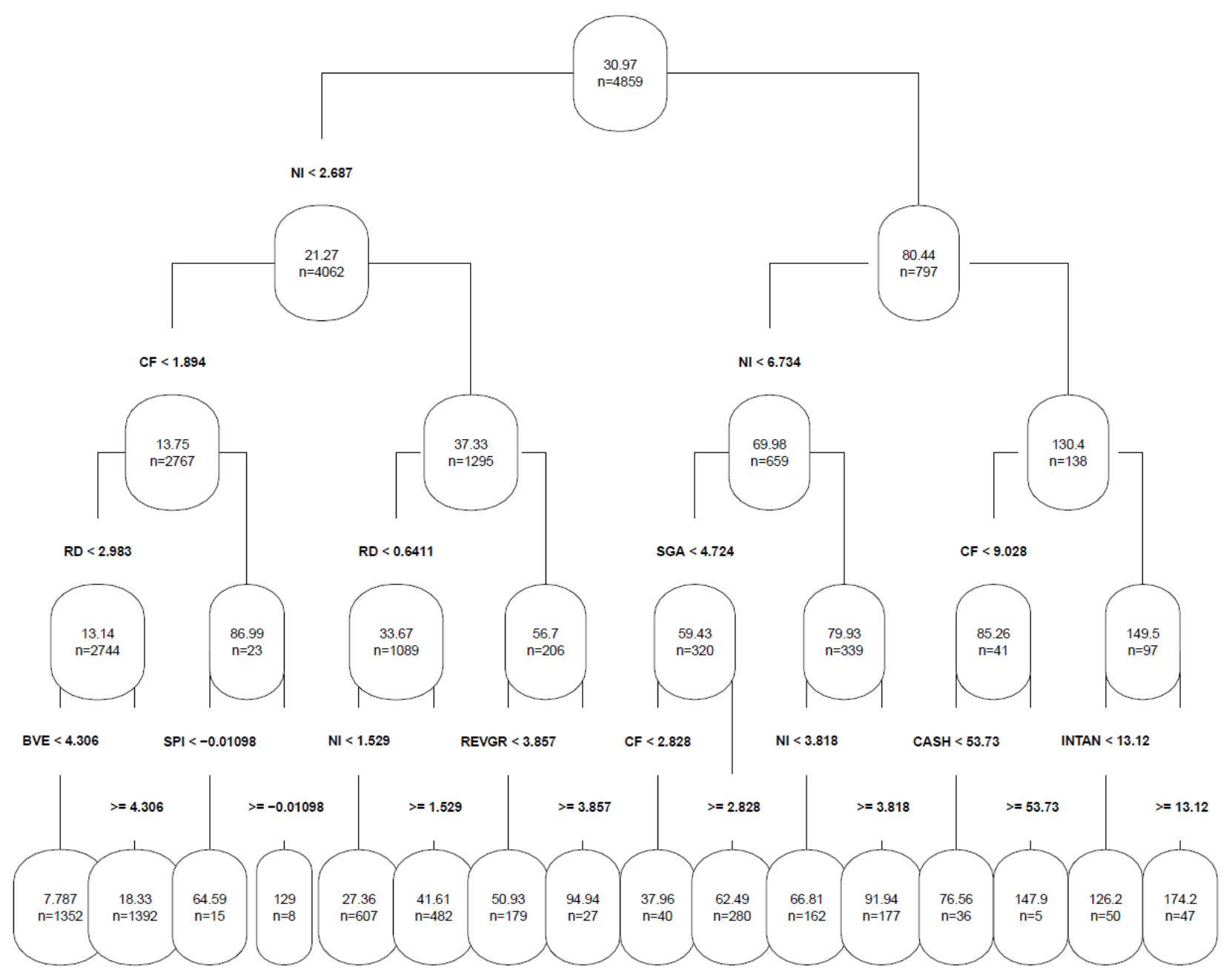

This figure presents one example tree using all 2014 data. Each round box (or "node") presents the predicted price and number of observations in that node. Each line (or "branch") reports the criterion on which the data are partitioned. The bottom two rows of nodes present the final predicted price for each observation based on the partitions. This example estimation allows a maximum of four splits and requires at least five observations in each node. 


\section{A.2 Validation tests for CART}

We validate our use of CART by showing (1) CART automatically identifies and incorporates nonlinearities and interactions, and (2) CART has higher combined value relevance than OLS specifications, which indicates CART permits the underlying value relevance of accounting amounts to manifest more fully.

As examples of CART automatically incorporating nonlinearities (interactions), we present the CART estimated marginal relations between $P$ and $N I$ and between $P$ and $C F$ (between $P$ and $C A S H$, for firms with $D I V=0$ and with $D I V>0$ ) for 1975, 1985, 1995, 2005, and 2014 (2014). ${ }^{33}$ See Appendix 1 for variable definitions. ${ }^{34}$

Figure A2.2, Panel A presents the marginal CART-estimated relation between $P$ and $N I$, conditional on the other accounting amounts and industry indicators. It reveals, consistent with prior research (Collins et al. 1999), that in each year there is little (a positive) relation between $P$ and $N I$ for loss (profit) firms. Panel B presents the conditional marginal relation between $P$ and $C F$. It reveals in 1975 and 1985 there is little conditional marginal relation. In 1995, 2005, and 2014 there is little (a positive) conditional marginal relation for negative (positive) $C F$ firms. ${ }^{35}$ Panel C presents the marginal relation between $P$ and $C A S H$, separately for firms with $D I V=0$ and $D I V>0$, conditional on the other accounting amounts and industry indicators. It reveals $C A S H$ has a significantly larger conditional marginal relation with $P$ for non-dividend paying firms, which is consistent with a higher marginal value of cash for financially constrained firms (Faulkender and Wang 2006). CART automatically discovers and incorporates the nonlinearities in Panels A and B and the interaction in Panel C.

We next show CART has higher value relevance than two OLS specifications. The first includes only NI and BVE as explanatory variables (Collins et al. 1997; Brown et al. 1999) (NIBVE):

$$
P_{i}=\beta_{0}+\beta_{1} N I_{i}+\beta_{2} B V E_{i}+\varepsilon_{i}
$$

The second includes interactions often specified in prior research either explicitly or implicitly, e.g., estimation by industry. Specifically, it contains the sixteen non-indicator accounting amounts, plus interactions of each with the ten industry indicators and with LOSS, which is an indicator variable that equals one if $N I<0$, and zero otherwise (Hayn 1995; Balachandran and Mohanram 2011) (All-OLS):

\footnotetext{
${ }^{33} \mathrm{We}$ do not present marginal relations for all accounting amounts and years because it is difficult to graph or summarize such a large number of relations.

${ }^{34}$ The $\mathrm{x}$-axis is $N I(C F)$ in Panel A (B). The $x$-axis lower (upper) bound represents the 2.5 (97.5) percentile for the year with the largest (smallest) 2.5 (97.5) percentile. The $y$-axis is the difference between the CART predicted price at the $x$ value and the minimum predicted price across the range of $x$.

${ }^{35}$ A stronger marginal relation between $C F$ and $P$ for positive $C F$ firms is consistent with financial statement analysis textbooks (Palepu and Healy 2008) that suggest earnings- and cash flow-based multiples are less useful when they are temporarily low. However, to our knowledge, the finding in Panel B is new to the literature.
} 


$$
\begin{gathered}
P_{i}=\beta_{0}+\beta_{1} L O S S_{i}+\sum_{j=1}^{10} \beta_{2 j} I N D 10_{j i}+\sum_{j=1}^{10} \sum_{k=1}^{12} \beta_{3 j k} I N D 10_{j i} \times V A R_{k i} \\
+\sum_{j=1}^{10} \sum_{k=1}^{12} \beta_{3 j k} I N D 10_{j i} \times V A R_{k i} \times L O S S_{i}+\varepsilon_{i}
\end{gathered}
$$

Panel D presents the mean OOS R ${ }^{2}$ from 1962 to 2014 for NIBVE, All-OLS, and CART. It reveals NIBVE's mean OOS $\mathrm{R}^{2}$ is $55.7 \%$. Perhaps surprisingly, All-OLS's mean OOS $\mathrm{R}^{2}$ is only $27.9 \%$, even though that specification includes fourteen more accounting amounts than NIBVE, industry effects, a loss indicator, and their interactions. This low mean OOS $\mathrm{R}^{2}$ reveals substantial overfitting in All-OLS, which results in poor out-of-sample explanatory power. ${ }^{36}$ Panel D also reveals that CART's mean OOS $\mathrm{R}^{2}$ is $69.8 \%$, which suggests it can accommodate more explanatory variables, as well as nonlinearities and interactions, without substantial overfitting. The difference in OOS $\mathrm{R}^{2}$ between CART and NIBVE (All-OLS), 14.1\% (41.9\%), is significant. 37

\footnotetext{
${ }^{36}$ Using in-sample adjusted $\mathrm{R}^{2}$ masks this overfitting. Untabulated findings reveal in-sample adjusted $\mathrm{R}^{2}$ for AllOLS is $71.8 \%$, which is substantially higher than its OOS $\mathrm{R}^{2}$ of $27.9 \%$. The untabulated NIBVE in-sample adjusted $\mathrm{R}^{2}$ is $55.9 \%$. These statistics reveal using in-sample adjusted $\mathrm{R}^{2}$ would lead to the incorrect inference that All-OLS has higher value relevance than NIBVE. In addition, when we estimate All-OLS excluding the loss indicator and its interaction terms, the in-sample adjusted $\mathrm{R}^{2}\left(\mathrm{OOS} \mathrm{R}^{2}\right)$ is $69.7 \%(53.2 \%)$, which indicates overfitting even when the loss indicator and its interactions are excluded from All-OLS (untabulated).

${ }^{37}$ We estimate OOS $\mathrm{R}^{2}$ for OLS specifications using ten-fold cross-validation, in which we randomly partition the data into ten equal-sized parts. For each part, we estimate the equation using data from the other nine parts and use the estimated equation to predict the price of the tenth part. We repeat this for all ten parts, so we hold out each part from estimation once. The sum of the mean squared price prediction error for observations of the held out parts, scaled by the variance of price, is the ten-fold cross validation estimate of OOS $\mathrm{R}^{2}$ (Hastie et al. 2001). We use outof-bag cross-validation for Equation (1) because it is the standard cross-validation methodology for CART. In untabulated tests, we find the higher mean OOS $\mathrm{R}^{2}$ of CART compared to NIBVE and All-OLS is robust to using ten-fold cross validation.
} 


\section{FIGURE A2.2: CART Validation}

Panel A: Conditional Marginal Relation between $P$ and $N I$

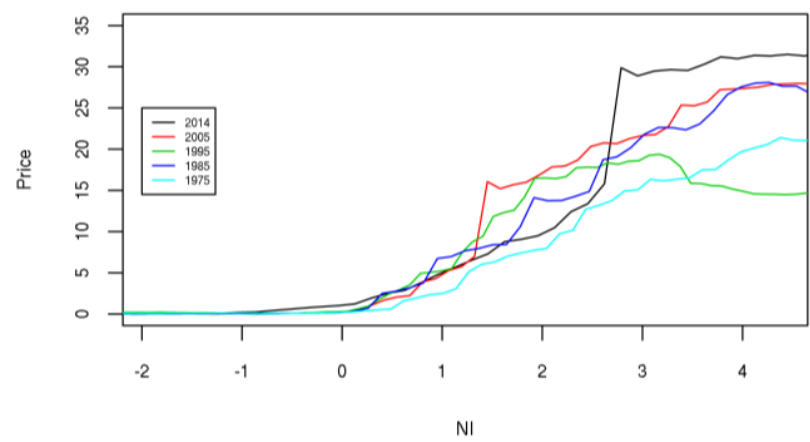

Panel B: Conditional Marginal Relation between $\boldsymbol{P}$ and $\boldsymbol{C F}$

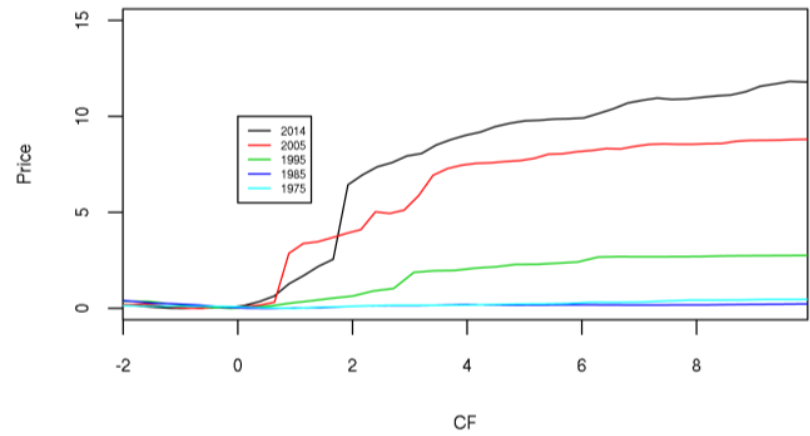

Panel C: Conditional Marginal Relation between $P$ and $C A S H$, for $D I V=0$ and $D I V>0$

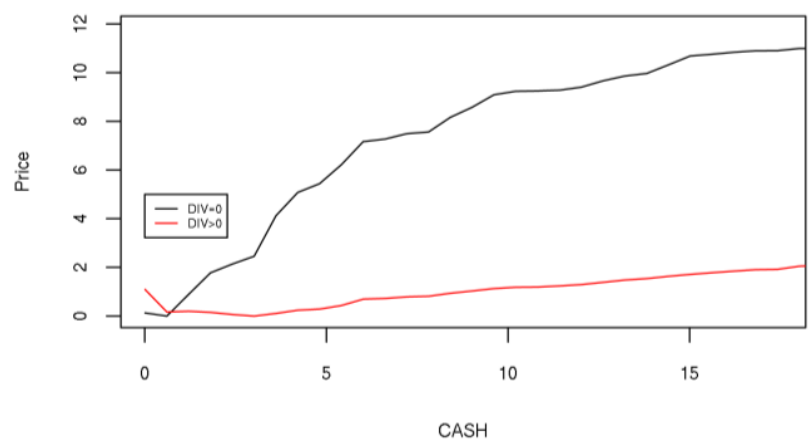

Panel D: Mean OOS R 1962 to 2014

\begin{tabular}{ll} 
Equation & OOS R-sq. \\
\hline NIBVE & 55.7 \\
All-OLS & 27.9 \\
CART & 69.8 \\
& \\
CART - NIBVE & $14.1 * * *$ \\
CART - All-OLS & $41.9 * * *$ \\
\hline
\end{tabular}

$*, * *$, and $* * *$ indicate two-tailed significance at the 10,5 , and 1 percent levels. 
FIGURE 1: Value Relevance of Individual Accounting Amounts

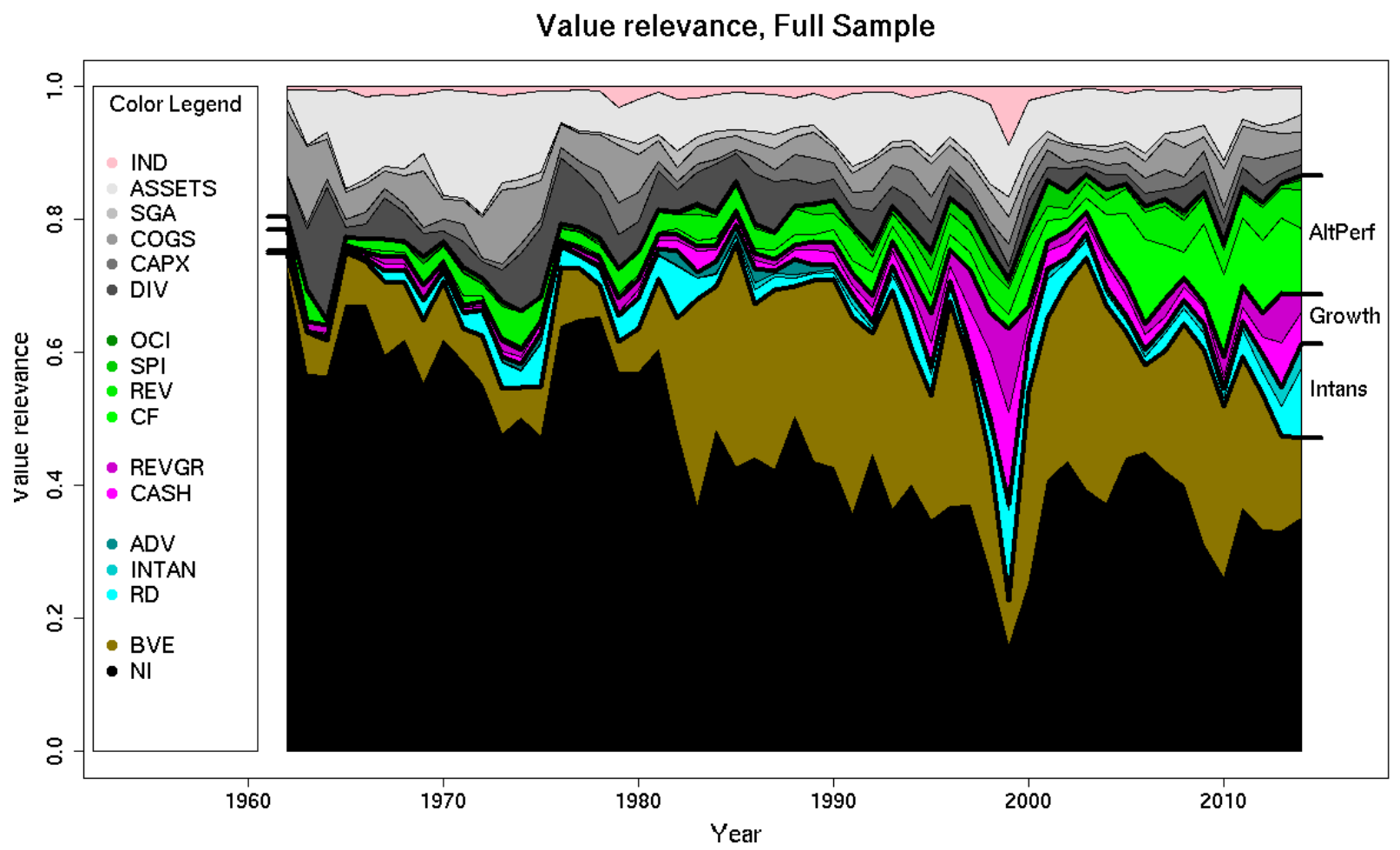

1960s

2010 s
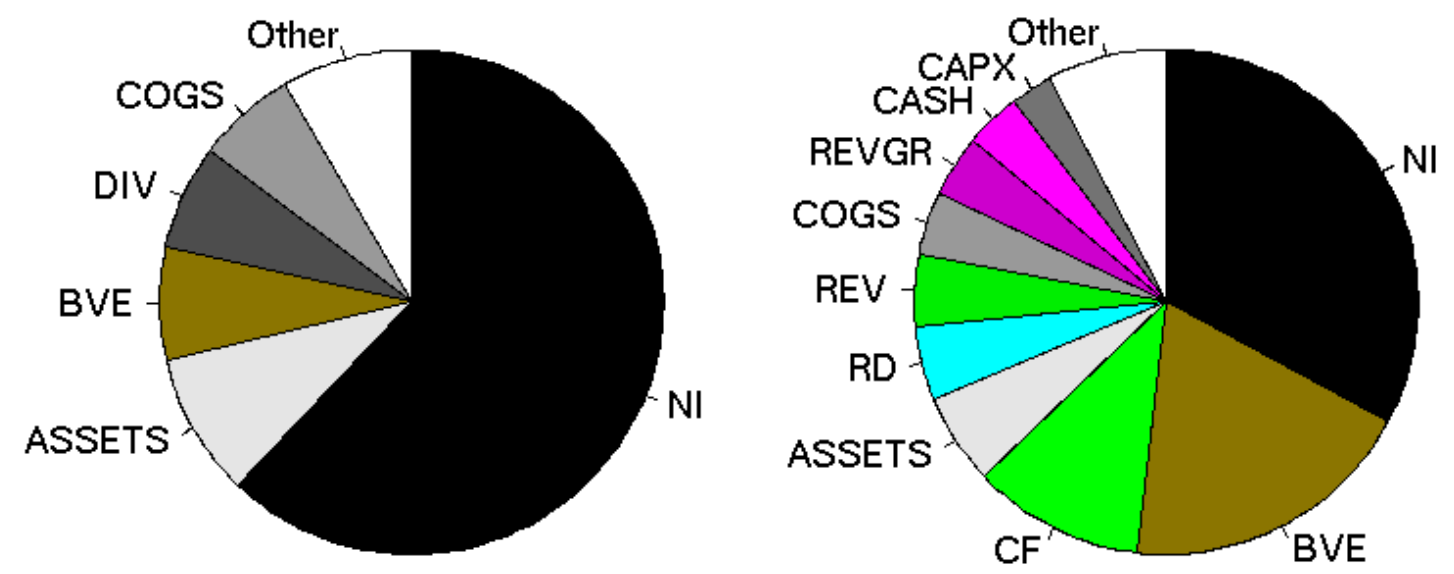

This figure presents value relevance of each accounting amount from 1962-2014. The graph presents value relevance for all accounting amounts. The pie chart presents in clockwise order the most value relevant accounting amounts in the 1960s and 2010s, up to the number required to explain at least 90 percent of combined value relevance. The rest of the accounting amounts are grouped in "Other". 
FIGURE 2: Value Relevance of Individual Accounting Amounts for New Economy, NonNew Economy Profit, and Non-New Economy Loss Firms

Panel A: New Economy firms

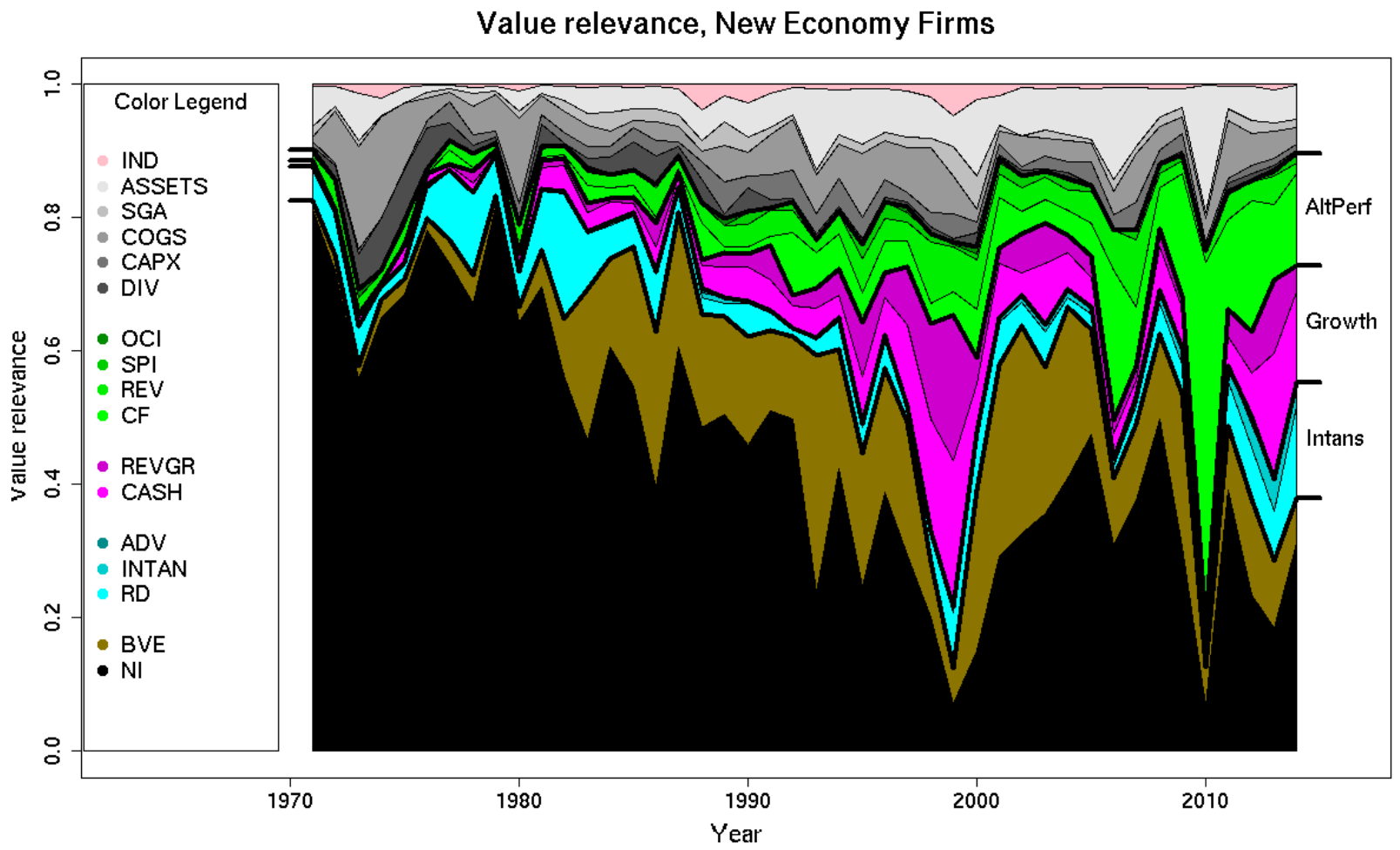

1970s

2010s
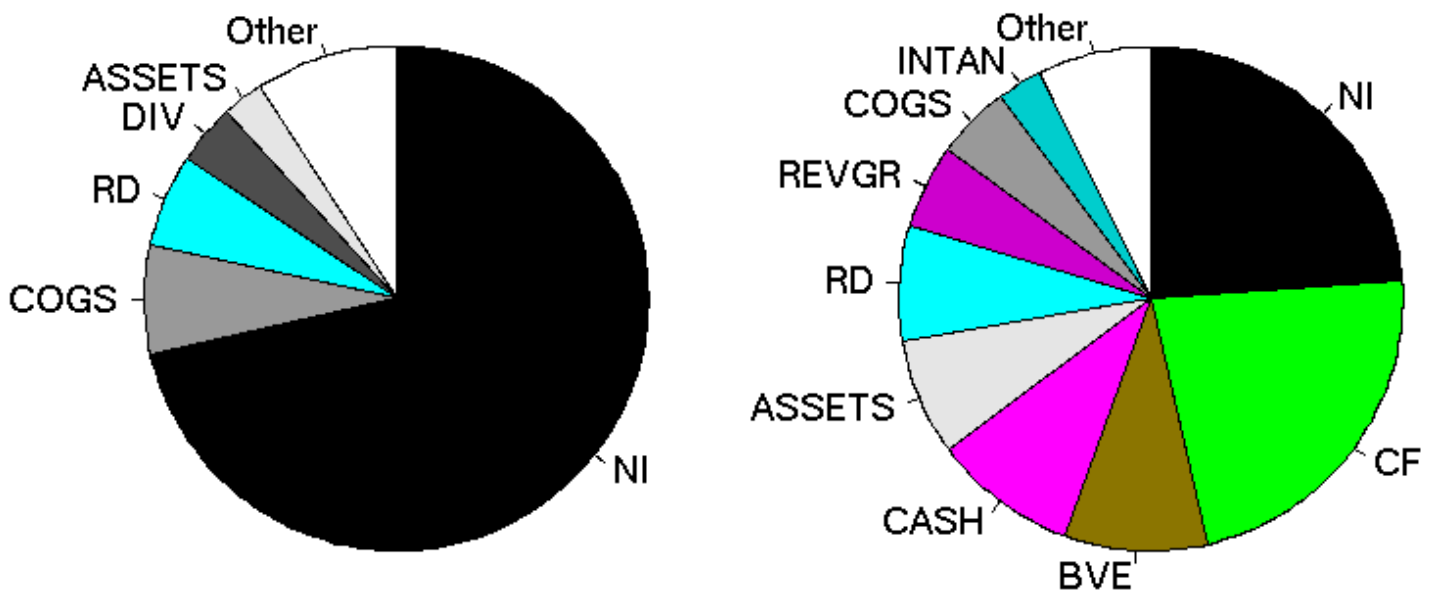
FIGURE 2: Value Relevance of Individual Accounting Amounts for New Economy, NonNew Economy Profit, and Non-New Economy Loss Firms (continued)

Panel B: Non-New Economy Profit firms

Value relevance, Non-New Economy Profit Firms

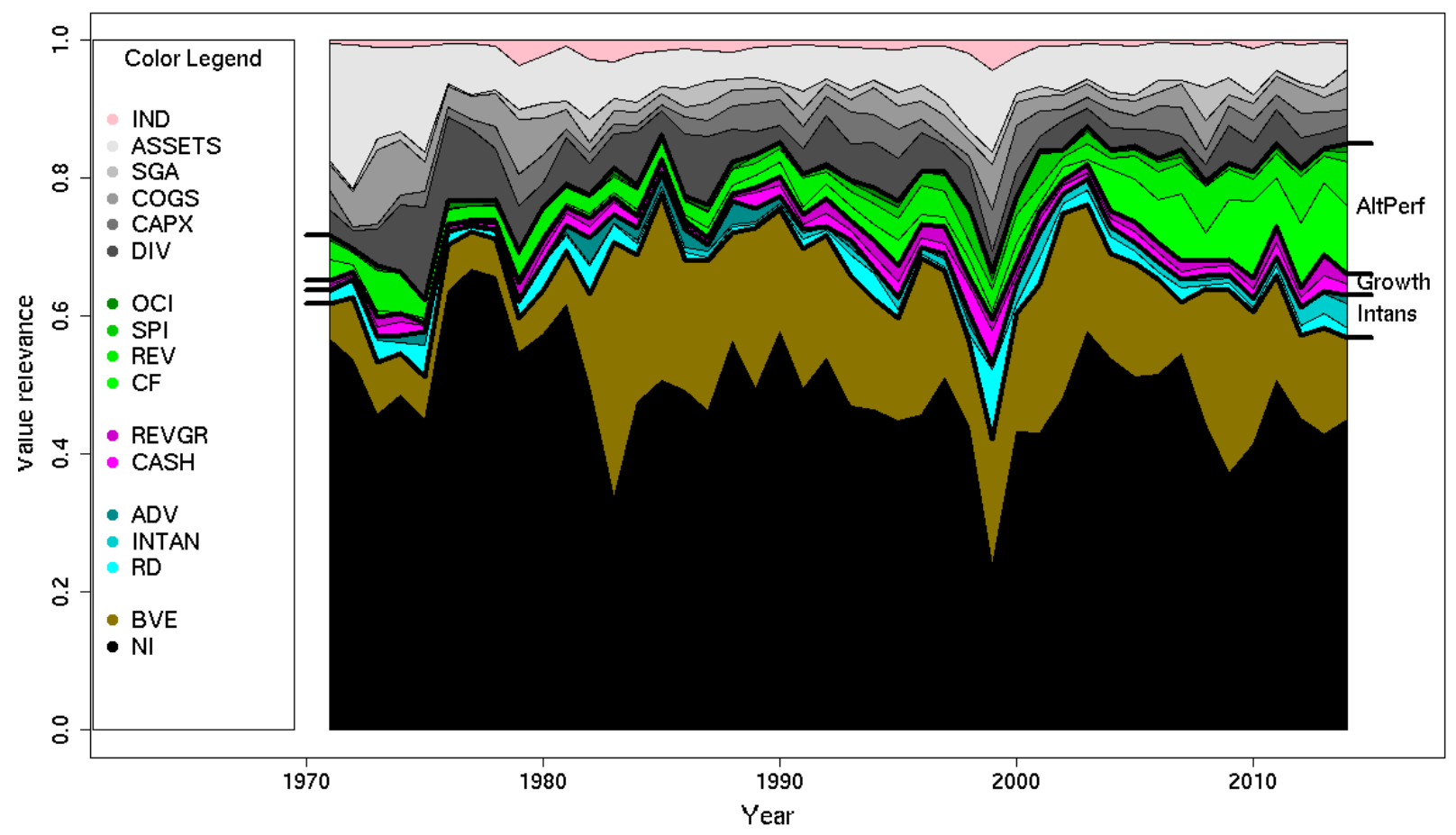

1970s

2010s
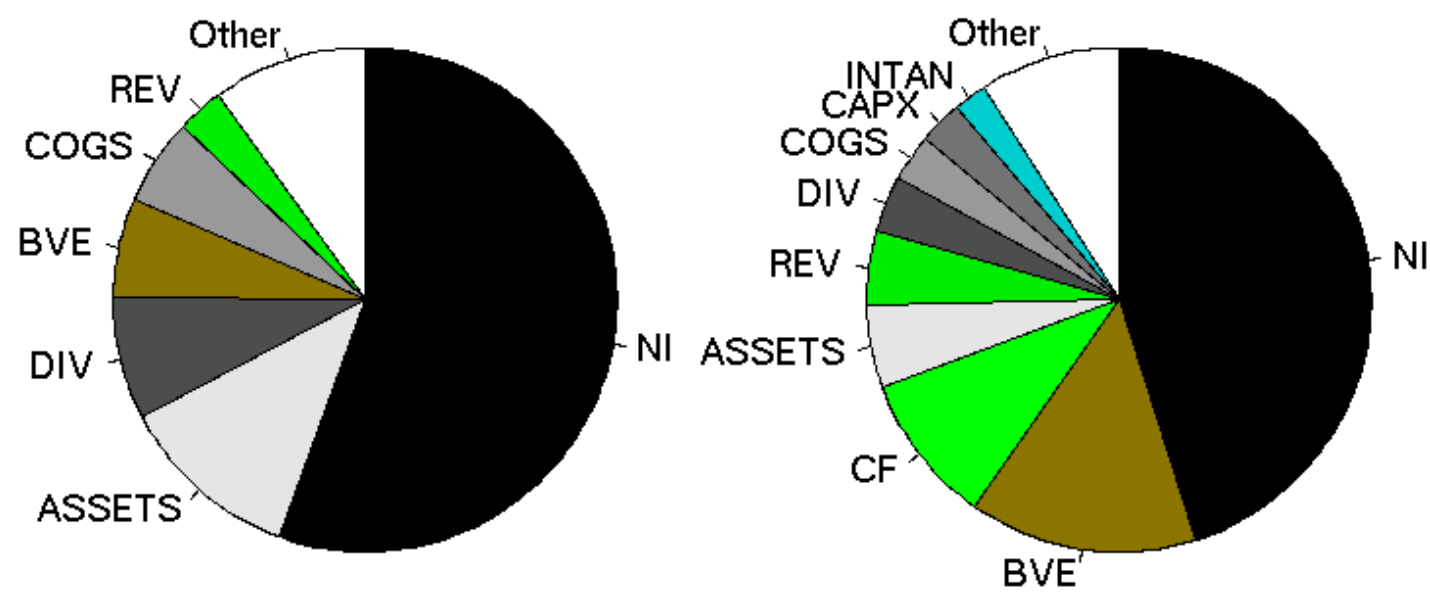
FIGURE 2: Value Relevance of Individual Accounting Amounts for New Economy, NonNew Economy Profit, and Non-New Economy Loss Firms (continued)

\section{Panel C: Non-New Economy Loss firms}

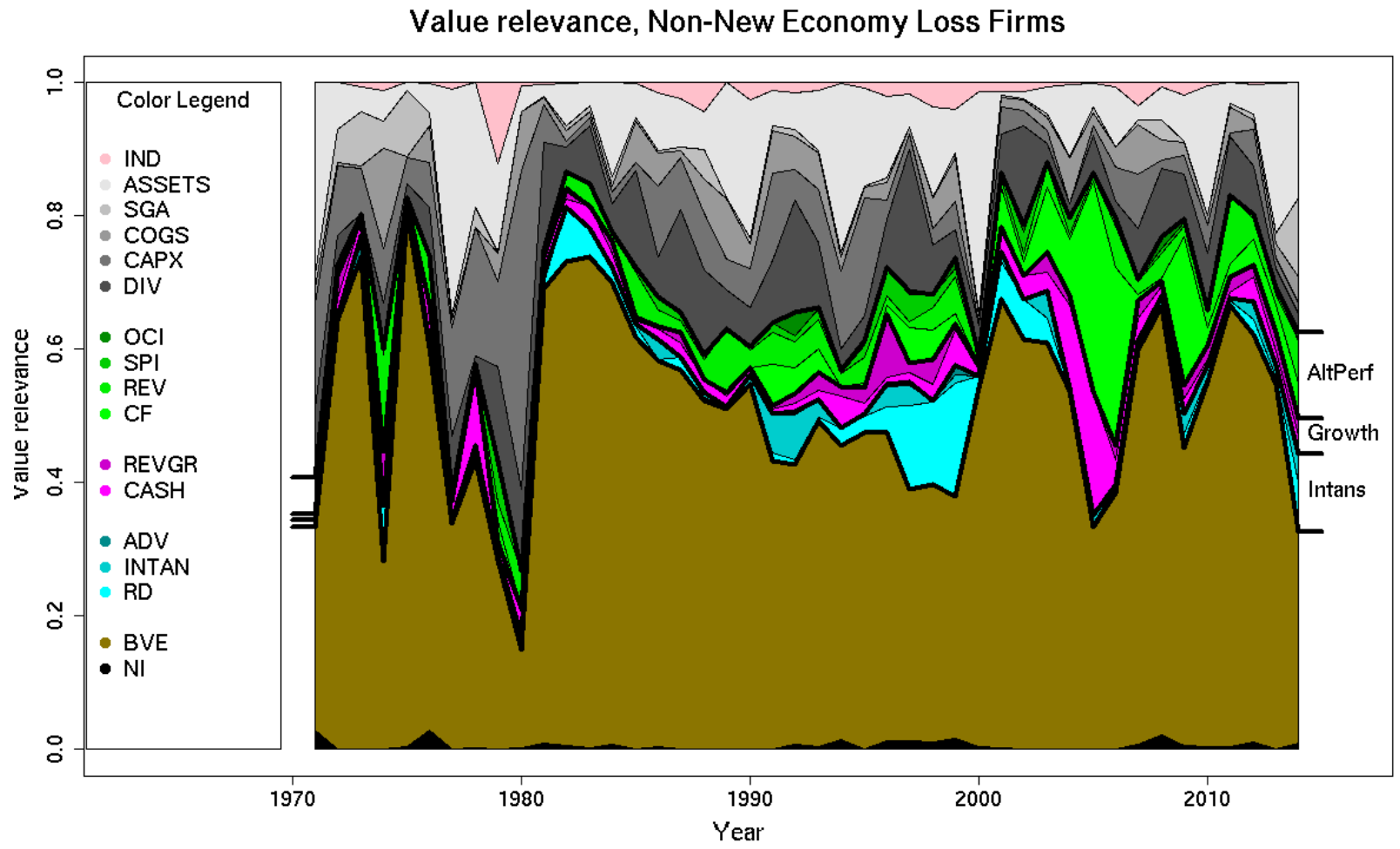

1970s

2010s
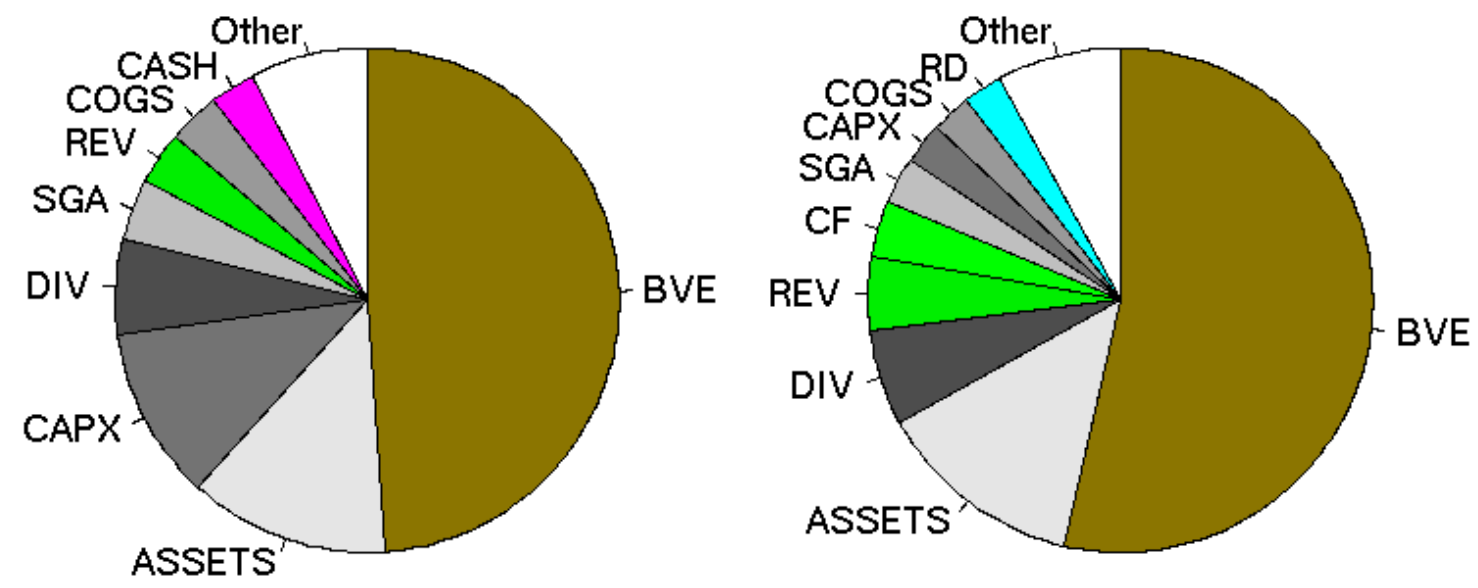

Panels A, B, and C present value relevance of each accounting amount for New Economy, NonNew Economy Profit, and Non-New Economy Loss firms from 1971-2014. The graph presents value relevance for all accounting amounts. The pie charts present in clockwise order the most value relevant accounting amounts in the 1970s and 2010s needed to explain at least 90 percent of combined value relevance. The rest of the accounting amounts are grouped in Other. 
FIGURE 3: Value Relevance of Individual Accounting Amounts for New Economy Profit and New Economy Loss Firms

\section{Panel A: New Economy Profit firms}

Value relevance, New Economy Profit Firms

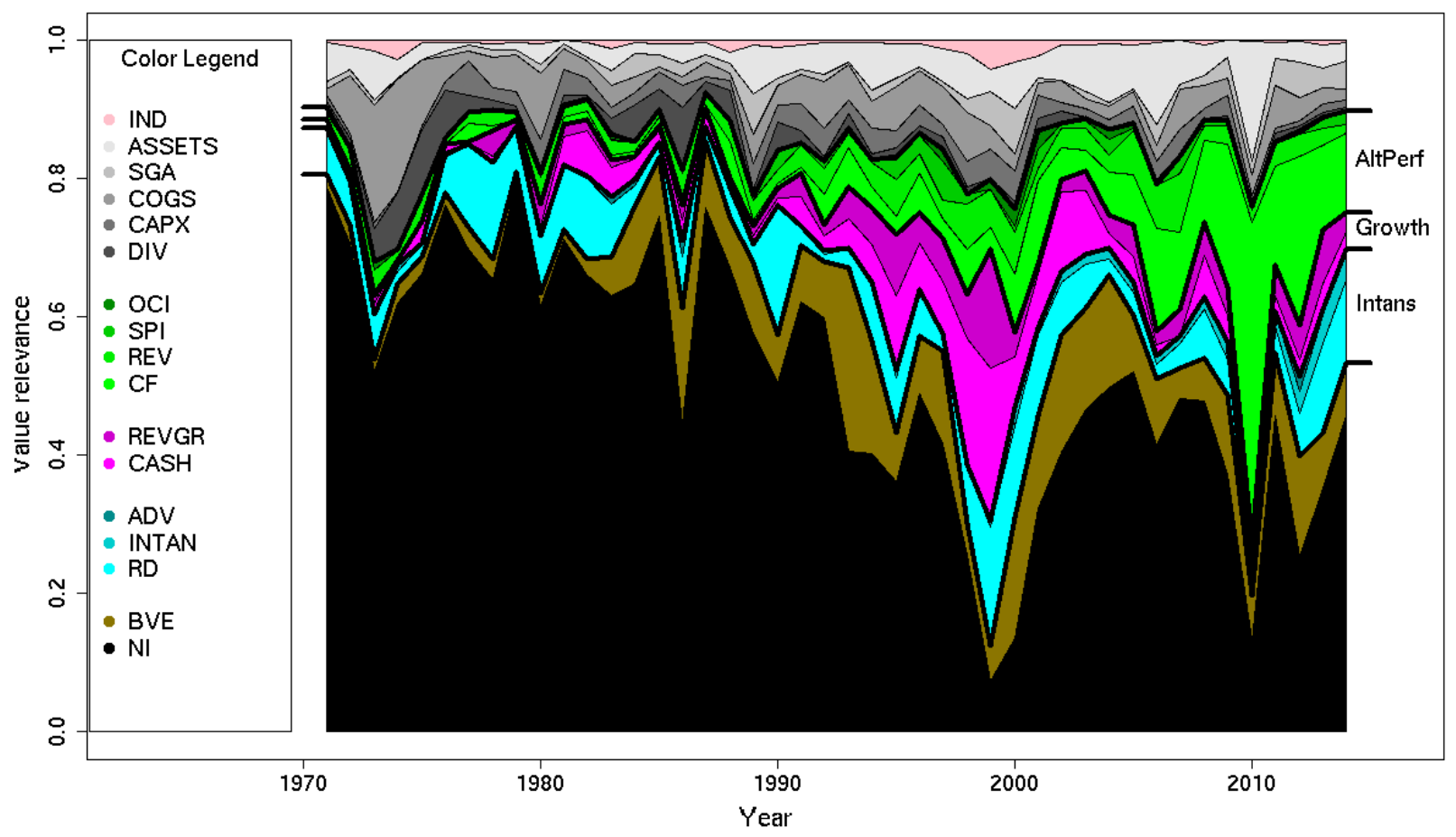

1970s

2010s
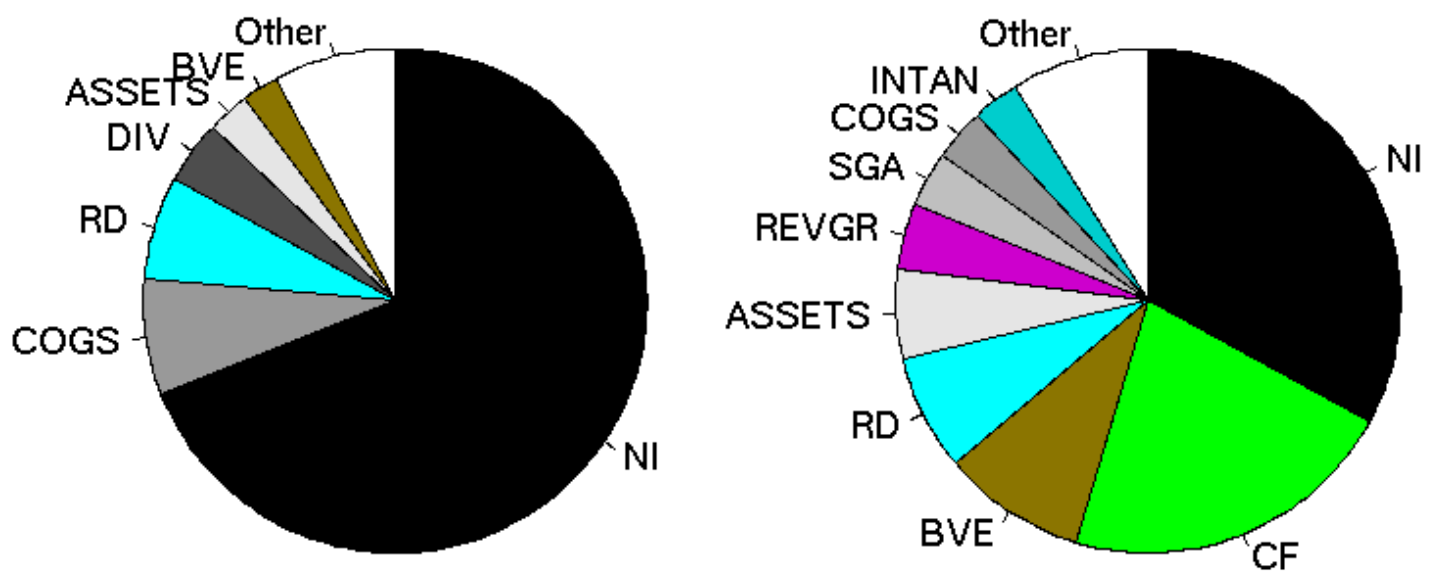
FIGURE 3: Value Relevance of Individual Accounting Amounts for New Economy Profit and New Economy Loss Firms (continued)

\section{Panel B: New Economy Loss firms}

Value relevance, New Economy Loss Firms

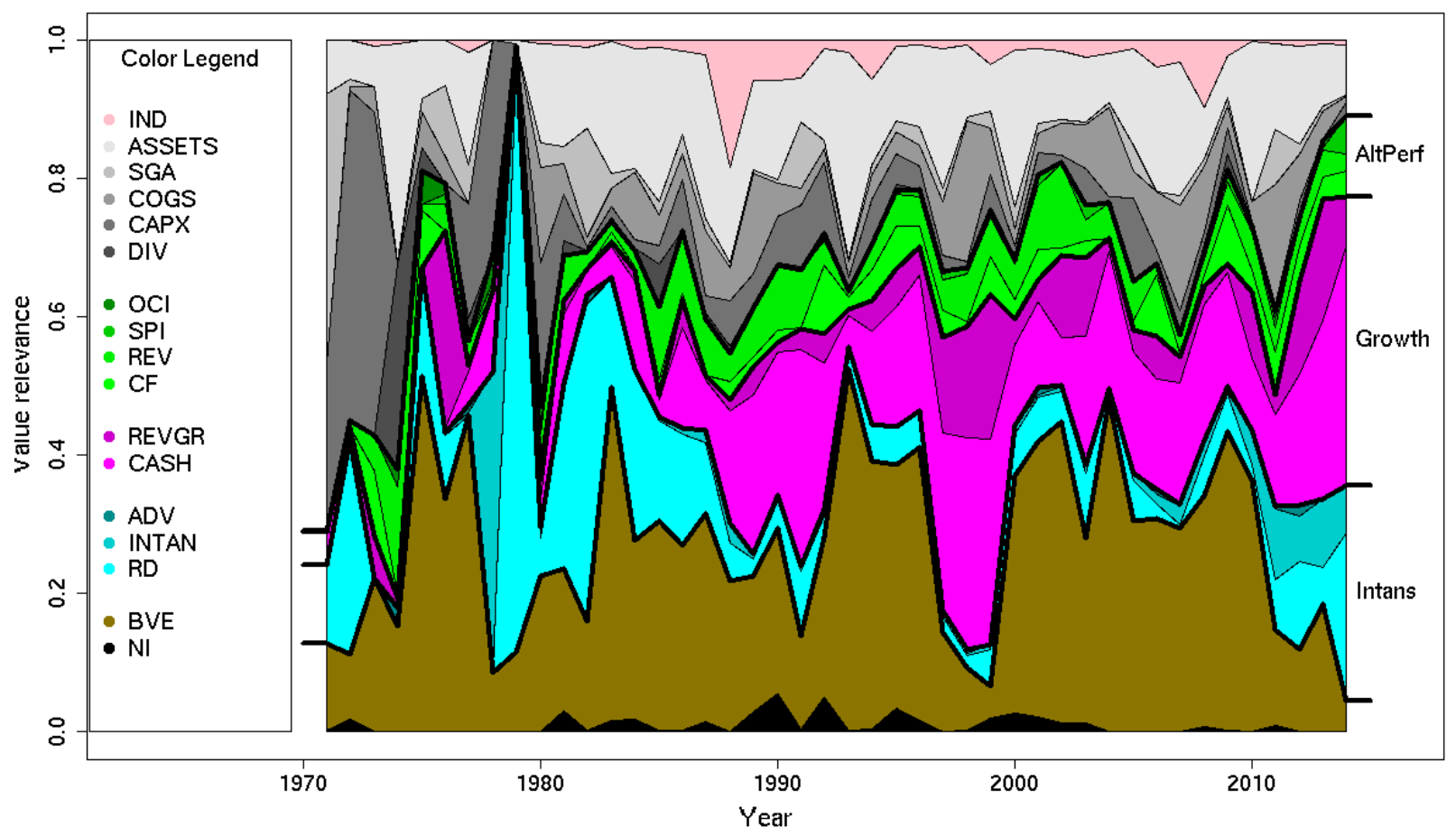

1970s

2010s
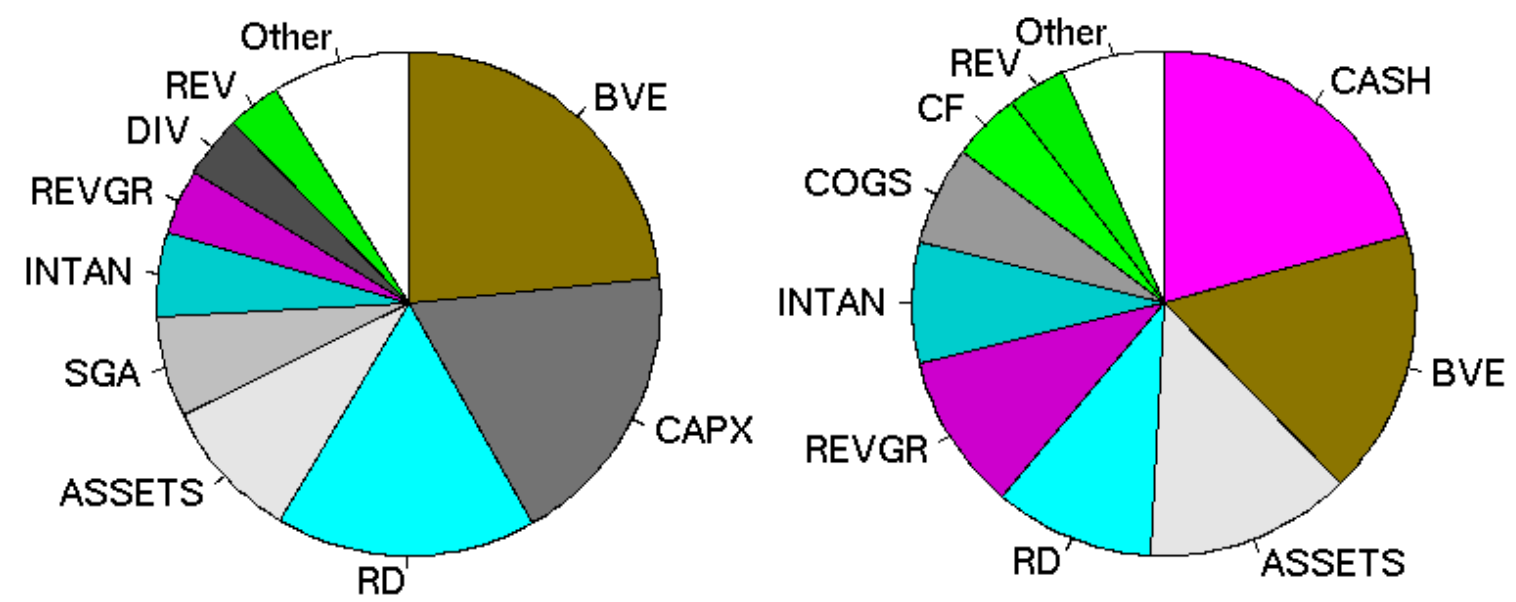

Panels A and B present value relevance of each accounting amount for New Economy Profit and Non-New Economy Loss firms from 1971-2014. The graph presents value relevance for all accounting amounts. The pie charts present in clockwise order the most value relevant accounting amounts in the 1970s and 2010s needed to explain at least 90 percent of combined value relevance. The rest of the accounting amounts are grouped in Other. 
TABLE 1: Descriptive Statistics

Panel A: Distributional statistics

\begin{tabular}{lrr} 
& Mean & St. Dev. \\
\hline$P$ & 18.89 & 19.57 \\
$N I$ & 0.90 & 1.97 \\
$B V E$ & 10.68 & 11.03 \\
$R D$ & 0.28 & 0.66 \\
$I N T A N$ & 1.79 & 4.65 \\
$A D V$ & 0.22 & 0.73 \\
$C A S H$ & 4.10 & 13.16 \\
$R E V G R$ & 2.17 & 6.28 \\
$C F$ & 1.82 & 4.01 \\
$R E V$ & 26.15 & 36.49 \\
SPI & -0.13 & 0.63 \\
OCI & -0.14 & 0.92 \\
DIV & 0.38 & 0.64 \\
$C A P X$ & 1.43 & 2.47 \\
$C O G S$ & 18.81 & 29.68 \\
SGA & 4.07 & 5.94 \\
ASSETS & 44.21 & 84.18 \\
\hline
\end{tabular}


TABLE 1: Descriptive Statistics (continued)

Panel B: Pearson and Spearman correlations

\begin{tabular}{|c|c|c|c|c|c|c|c|c|c|c|c|c|c|c|c|c|}
\hline & 1 & 2 & 3 & 4 & 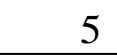 & 6 & & 8 & & 10 & 11 & 13 & 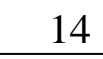 & 15 & 16 & 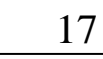 \\
\hline $1 P$ & & 61 & 0.63 & .23 & .33 & 14 & .21 & 24 & .41 & & $1-0.08$ & 0.50 & .35 & .31 & .30 & .33 \\
\hline $2 N I$ & 0.72 & & 0.65 & 0.08 & & & & & & & 8 & 5 & 35 & 37 & 29 & 0.38 \\
\hline $3 B V$ & 73 & .70 & & 16 & .24 & 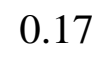 & & & & & & & & & 3 & J \\
\hline $4 R D$ & 0.03 & -0.10 & -0.09 & & 0.08 & & 0.00 & & & & 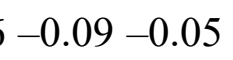 & 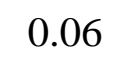 & 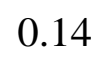 & & 28 & 0.03 \\
\hline $5 I$ & & 01 & 0.17 & 0 & & & & & & & & & & & & 14 \\
\hline $6 A L$ & & .03 & 0.02 & 0.08 & 0.11 & & 0.01 & 3 & & 31 & 0.05 & 0.10 & 0.15 & .25 & .50 & 0.03 \\
\hline $7 C$ & & .37 & 0.52 & 0.07 & 0.14 & 0.09 & & & $0.2 J$ & 0 & -0.03 & 0.23 & 0 & 16 & 20 & .78 \\
\hline & & 0.46 & & & & & 7 & & & & & & 7 & & & 18 \\
\hline $9 C F$ & & 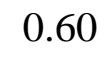 & 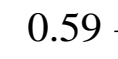 & 9 & .17 & 0.02 & 0. & 0.23 & & 7 & $-0.00-0.09$ & 8 & 41 & & .22 & 0.28 \\
\hline$R$ & & 0.60 & 0.71 & .08 & .24 & 0.11 & 0.36 & 0.46 & 0. & & $-0.05-0.11$ & 0.36 & 0.48 & 98 & 0.71 & 0.34 \\
\hline$S P I$ & & 0.24 & 0.07 & .10 & 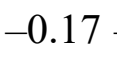 & -0.03 & 0.01 & 0.08 & 0.04 & 0.02 & 0.05 & 0.02 & .0 & & .0 & .01 \\
\hline $2 O C I$ & & -0.12 & -0.10 & $0 .($ & $-c$ & 0 & -0. & -0.01 & & 0 & 0.00 & -0.06 & . & & .09 & -0.07 \\
\hline$D I V$ & & & 0.65 & -0 . & & & & & & 0.49 & $0.09-0.12$ & & 0.35 & & 21 & 0.38 \\
\hline$+C A$ & & 36 & .44 & 0.05 & $\tau$ & 0 & 0.12 & 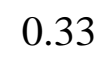 & 0.45 & 0.60 & $0.01-0.11$ & 0.26 & & .46 & .28 & 0.13 \\
\hline $5 C O G$ & & 0.51 & . & -0.09 & & & & & & 0.97 & $0.03-0.12$ & 0.44 & 0.59 & & 0.61 & 0.29 \\
\hline $16 S G A$ & & 0.27 & 0.36 & 0.20 & 25 & & & & 0 . & 0.61 & $-0.04-0.06$ & 0.16 & 0.34 & .53 & & 0.24 \\
\hline 17 ASSETS & .65 & 0.61 & 0.85 & -0.22 & 0.22 & 0.04 & 0.54 & 0.32 & 0.56 & 0.74 & $0.03-0.14$ & 0.61 & 0.38 & 0.67 & 0.34 & \\
\hline
\end{tabular}

This table presents descriptive statistics for the 227,030 firm-years for 21,515 firms from 1962-2014. See Appendix 1 for definition of the variables. Panel A presents distributional statistics and Panel B presents correlations, with Pearson (Spearman) correlations above (below) the main diagonal. 


\section{TABLE 2: Combined Value Relevance of Accounting Amounts}

\begin{tabular}{lrrrrr} 
& Mean & SD & & Trend & $(\mathrm{t}-\mathrm{stat})$ \\
\cline { 2 - 3 } \cline { 6 - 7 } All & 69.8 & 8.9 & & $0.238^{* * *}$ & $(3.25)$ \\
\hline $1960 \mathrm{~s}$ & 57.7 & 5.6 & & -0.372 & $(-0.40)$ \\
$1970 \mathrm{~s}$ & 67.2 & 7.9 & & $1.845 * *$ & $(2.84)$ \\
$1980 \mathrm{~s}$ & 78.2 & 3.7 & & $0.934 * * *$ & $(3.41)$ \\
$1990 \mathrm{~s}$ & 70.5 & 10.1 & & $-2.683 * * *$ & $(-3.79)$ \\
$2000 \mathrm{~s}$ & 71.7 & 5.2 & & 0.746 & $(1.38)$ \\
$2010 \mathrm{~s}$ & 72.3 & 0.4 & & 0.165 & $(1.74)$ \\
\hline
\end{tabular}

This table presents results for combined value relevance of accounting information. Each year from 1962-2014, we estimate OOS $\mathrm{R}^{2}$ using CART (Appendix 2). Table values present mean, standard deviation, and trend of OOS $\mathrm{R}^{2}$. Trend represents estimates of $\beta_{1}$ in Equation (2), the explanatory power over time:

$$
\operatorname{OOSR2}_{t}=\beta_{0}+\beta_{1} Y E A R_{t}+\varepsilon_{t}
$$

OOSR2 is the OOS $\mathrm{R}^{2}$ in percentages and $Y E A R$ is year. *,**, and *** indicate two-tailed significance at the 10,5 , and 1 percent levels. 
TABLE 3: Value Relevance of Individual Accounting Amounts

Panel A: Mean value relevance

\begin{tabular}{lr|rrrrrr} 
& All years & $1960 \mathrm{~s}$ & $1970 \mathrm{~s}$ & $1980 \mathrm{~s}$ & $1990 \mathrm{~s}$ & $2000 \mathrm{~s}$ & $2010 \mathrm{~s}$ \\
\hline NI & 46.1 & 62.1 & 57.2 & 47.3 & 35.1 & 38.8 & 32.8 \\
$B V E$ & 17.2 & 7.3 & 6.6 & 21.8 & 22.5 & 24.9 & 19.1 \\
$R D$ & 3.0 & 0.9 & 3.1 & 2.8 & 3.7 & 3.0 & 4.7 \\
INTAN & 0.6 & 0.1 & 0.1 & 0.3 & 0.7 & 0.8 & 2.1 \\
ADV & 0.5 & 0.0 & 0.4 & 1.3 & 0.3 & 0.2 & 0.2 \\
$C A S H$ & 2.2 & 0.7 & 0.7 & 1.6 & 4.5 & 2.5 & 3.6 \\
REVGR & 2.0 & 1.1 & 0.9 & 1.0 & 4.1 & 1.7 & 4.0 \\
$C F$ & 3.1 & 0.4 & 0.6 & 0.9 & 2.5 & 6.7 & 10.9 \\
REV & 3.1 & 1.8 & 2.8 & 3.1 & 3.2 & 3.4 & 4.5 \\
SPI & 0.7 & 0.0 & 0.1 & 0.4 & 1.5 & 1.3 & 0.7 \\
OCI & 0.4 & 0.2 & 0.6 & 0.4 & 0.4 & 0.3 & 0.4 \\
DIV & 4.5 & 6.6 & 6.1 & 5.2 & 3.5 & 2.5 & 2.3 \\
CAPX & 2.1 & 1.1 & 2.0 & 2.2 & 2.5 & 2.0 & 2.6 \\
COGS & 4.2 & 6.4 & 6.0 & 3.0 & 3.7 & 2.6 & 4.1 \\
SGA & 1.2 & 1.1 & 0.7 & 1.5 & 1.1 & 1.3 & 1.4 \\
ASSETS & 8.1 & 9.3 & 11.0 & 5.9 & 8.6 & 7.2 & 5.9 \\
\hline IND & 1.2 & 0.9 & 1.0 & 1.3 & 2.1 & 0.9 & 0.4 \\
\hline Intans & 4.0 & 1 & 3.6 & 4.5 & 4.7 & 4 & 7.1 \\
Growth & 4.2 & 1.8 & 1.6 & 2.6 & 8.6 & 4.2 & 7.6 \\
AltPerf & 7.2 & 2.5 & 4.1 & 4.7 & 7.5 & 11.6 & 16.6 \\
\hline
\end{tabular}


TABLE 3: Value Relevance of Individual Accounting Amounts (continued) Panel B: Trends in value relevance

\begin{tabular}{lcr} 
& \multicolumn{1}{c}{ Coef. } & (t-stat) \\
\hline$N I$ & $-0.657^{* * *}$ & $(-9.91)$ \\
$B V E$ & $0.390^{* * *}$ & $(5.68)$ \\
$R D$ & $0.053^{* *}$ & $(2.46)$ \\
INTAN & $0.032^{* * *}$ & $(8.52)$ \\
ADV & 0.000 & $(-0.08)$ \\
CASH & $0.077^{* * *}$ & $(4.18)$ \\
REVGR & $0.060^{* * *}$ & $(3.58)$ \\
CF & $0.197^{* * *}$ & $(9.51)$ \\
REV & $0.042^{* * *}$ & $(4.35)$ \\
SPI & $0.029^{* * *}$ & $(4.87)$ \\
OCI & -0.001 & $(-0.26)$ \\
DIV & $-0.104^{* * *}$ & $(-4.24)$ \\
CAPX & $0.023^{* *}$ & $(2.44)$ \\
COGS & $-0.072^{* * *}$ & $(-3.91)$ \\
SGA & $0.011^{*}$ & $(1.83)$ \\
ASSETS & $-0.083^{* * *}$ & $(-2.85)$ \\
\hline IND & 0.002 & $(0.15)$ \\
\hline Intans & $0.085^{* * *}$ & $(3.59)$ \\
Growth & $0.137^{* * *}$ & $(4.02)$ \\
AltPerf & $0.268^{* * *}$ & $(12.32)$ \\
\hline
\end{tabular}

Panel C: Trends in number of value relevant accounting amounts

\begin{tabular}{lll} 
Threshold (Percent) & Coef. & (t-stat) \\
\hline 50 & $0.031^{* * *}$ & $(7.67)$ \\
75 & $0.051^{* * *}$ & $(6.18)$ \\
80 & $0.060^{* * *}$ & $(6.37)$ \\
90 & $0.093^{* * *}$ & $(10.03)$ \\
95 & $0.086^{* * *}$ & $(8.87)$ \\
\hline
\end{tabular}




\section{TABLE 3: Value Relevance of Individual Accounting Amounts (continued)}

This table presents results for value relevance of accounting information from 1962-2014. Panel A, reports the mean value relevance for each of the sixteen non-indicator accounting amounts plus industry across time.

Panel B presents estimates of $\beta_{1}$ from the following regression:

$$
V R_{t}=\beta_{0}+\beta_{1} Y E A R_{t}+\varepsilon_{t}
$$

$V R_{t}$ is the value relevance of a given accounting amount in year $t$, which is the share (in percent) of the total increase in mean squared error from randomly assigning the accounting amount, and $Y E A R_{t}$ is fiscal year $t$. For groups of accounting amounts, Intans refers to sum of value relevance of $R D, I N T A N$, and $A D V$, Growth refers to sum of value relevance of $C A S H$ and $R E V G R$, and AltPerf refers to sum of value relevance of $C F, R E V, S P I$, and $O C I$.

Panel C presents estimates of $\beta_{1}$ from the following regression:

$$
N U M V R_{t}=\beta_{0}+\beta_{1} Y E A R_{t}+\varepsilon_{t}
$$

$N U M V R_{t}$ is the number of value relevant accounting amounts in year $t$, which is the number of accounting amounts required to obtain 50,75, 80,90, and 95 percent share of combined value relevance, and $Y E A R_{t}$ is fiscal year $t .{ }^{*}, * *$, and $* * *$ indicate two-tailed significance at the 10 , 5 , and 1 percent levels. 
TABLE 4: Descriptive Statistics for New Economy, Non-New Economy Profit, and NonNew Economy Loss Firms

Panel A: Proportion of total population and time trend

\begin{tabular}{lrrrrr} 
& \multicolumn{3}{c}{ Mean proportion } & & \\
\cline { 2 - 4 } & All years & $1970 \mathrm{~s}$ & $2010 \mathrm{~s}$ & \multicolumn{1}{c}{ Trend } & (t-stat) \\
\hline New Economy & 30.8 & 11.1 & 38.0 & $0.750^{* * *}$ & $(10.84)$ \\
Non-NE Profit & 58.9 & 82.5 & 51.3 & $-0.855^{* * *}$ & $(-9.04)$ \\
Non-NE Loss & 10.3 & 6.5 & 10.6 & $0.106^{* * *}$ & $(2.74)$ \\
\hline
\end{tabular}

Panel B: Distributional statistics by firm group

\begin{tabular}{|c|c|c|c|c|c|c|}
\hline & \multicolumn{2}{|c|}{ New Economy } & \multicolumn{2}{|c|}{ Non-NE Profit } & \multicolumn{2}{|c|}{ Non-NE Loss } \\
\hline & Mean & $\mathrm{SD}$ & Mean & $\overline{\mathrm{SD}}$ & Mean & $\mathrm{SD}$ \\
\hline$P$ & 12.95 & 17.80 & 23.61 & 19.64 & 8.11 & 10.69 \\
\hline$N I$ & 0.04 & 1.58 & 1.79 & 1.65 & -1.34 & 1.74 \\
\hline$B V E$ & 5.22 & 7.31 & 14.24 & 11.50 & 6.72 & 8.33 \\
\hline$R D$ & 0.46 & 0.77 & 0.20 & 0.59 & 0.17 & 0.53 \\
\hline INTAN & 1.40 & 4.17 & 2.14 & 5.08 & 1.64 & 4.33 \\
\hline$A D V$ & 0.12 & 0.48 & 0.29 & 0.86 & 0.22 & 0.71 \\
\hline $\mathrm{CASH}$ & 2.04 & 4.05 & 5.76 & 17.30 & 2.54 & 7.09 \\
\hline$R E V G R$ & 0.96 & 3.63 & 3.30 & 7.09 & -0.71 & 6.10 \\
\hline$C F$ & 0.70 & 2.39 & 2.68 & 4.71 & 0.75 & 3.20 \\
\hline$R E V$ & 10.75 & 19.87 & 34.78 & 40.78 & 22.99 & 33.38 \\
\hline$S P I$ & -0.15 & 0.62 & -0.04 & 0.36 & -0.59 & 1.29 \\
\hline$O C I$ & -0.07 & 0.70 & -0.18 & 1.00 & -0.15 & 1.09 \\
\hline$D I V$ & 0.11 & 0.38 & 0.56 & 0.72 & 0.14 & 0.39 \\
\hline$C A P X$ & 0.71 & 1.60 & 1.85 & 2.77 & 1.11 & 2.13 \\
\hline$C O G S$ & 7.11 & 15.17 & 25.03 & 33.60 & 18.18 & 28.15 \\
\hline$S G A$ & 2.45 & 3.89 & 4.93 & 6.66 & 3.76 & 5.50 \\
\hline ASSETS & 14.79 & 34.74 & 64.60 & 103.70 & 33.75 & 63.68 \\
\hline
\end{tabular}

This table presents descriptive statistics for New Economy, Non-New Economy Profit, and NonNew Economy Loss firms. Panel A presents subsample composition from 1971-2014.

Proportion is the mean proportion of firms of the subsample across years, and trend is its trend over time. Panel B presents distributional statistics. *, **, and *** indicate two-tailed significance at the 10,5 , and 1 percent levels. 
TABLE 5: Value Relevance of Individual Accounting Amounts for New Economy, Non-New Economy Profit, and Non-New Economy Loss Firms

Panel A: Mean value relevance by firm group

\begin{tabular}{|c|c|c|c|c|c|c|c|c|c|}
\hline & \multicolumn{3}{|c|}{ New Economy } & \multicolumn{3}{|c|}{ Non-New Economy, Profit } & \multicolumn{3}{|c|}{ Non-New Economy, Loss } \\
\hline & All years & 1970s & $2010 \mathrm{~s}$ & All years & 1970s & $2010 \mathrm{~s}$ & All years & 1970s & $2010 \mathrm{~s}$ \\
\hline$N I$ & 45.4 & 71.4 & 23.8 & 49.5 & 55.6 & 45.0 & 0.6 & 0.7 & 0.6 \\
\hline$B V E$ & 13.3 & 2.4 & 9.3 & 15.5 & 6.3 & 14.7 & 51.4 & 48.9 & 53.7 \\
\hline$R D$ & 5.4 & 6.0 & 7.4 & 1.9 & 2.1 & 1.4 & 2.8 & 1.3 & 2.5 \\
\hline INTAN & 0.8 & 0.1 & 3.0 & 0.9 & 0.1 & 2.2 & 1.2 & 0.2 & 2.0 \\
\hline$A D V$ & 0.2 & 0.2 & 0.2 & 0.2 & 0.2 & 0.2 & 0.2 & 0.2 & 0.2 \\
\hline $\mathrm{CASH}$ & 5.1 & 0.8 & 9.2 & 1.5 & 0.8 & 1.8 & 2.9 & 2.9 & 2.1 \\
\hline$R E V G R$ & 3.4 & 0.5 & 5.4 & 1.3 & 0.8 & 1.9 & 1.6 & 1.5 & 2.3 \\
\hline$C F$ & 5.9 & 0.5 & 22.5 & 3.0 & 0.9 & 9.6 & 3.6 & 0.5 & 3.5 \\
\hline$R E V$ & 3.2 & 1.7 & 2.8 & 3.2 & 3.0 & 4.8 & 3.3 & 3.4 & 4.7 \\
\hline$S P I$ & 0.5 & 0.0 & 0.5 & 0.8 & 0.0 & 0.9 & 0.9 & 0.7 & 0.3 \\
\hline$O C I$ & 0.3 & 0.4 & 0.2 & 0.6 & 0.6 & 0.6 & 0.4 & 0.4 & 0.3 \\
\hline$D I V$ & 1.8 & 3.8 & 0.8 & 5.2 & 7.9 & 3.7 & 7.7 & 6.2 & 6.1 \\
\hline$C A P X$ & 1.9 & 1.0 & 0.9 & 2.7 & 2.1 & 2.8 & 6.9 & 11.1 & 2.6 \\
\hline COGS & 5.1 & 7.0 & 4.7 & 3.2 & 5.6 & 2.9 & 3.5 & 3.3 & 2.6 \\
\hline$S G A$ & 1.4 & 0.8 & 1.4 & 1.5 & 0.8 & 1.4 & 1.6 & 3.9 & 3.0 \\
\hline ASSETS & 5.3 & 2.7 & 7.5 & 7.3 & 11.7 & 5.3 & 10.2 & 12.9 & 13.3 \\
\hline$I N D$ & 0.9 & 0.6 & 0.4 & 1.2 & 1.1 & 0.6 & 1.3 & 1.7 & 0.2 \\
\hline Intans & 6.3 & 6.3 & 10.6 & 3.6 & 2.7 & 4.0 & 4.2 & 2.1 & 4.6 \\
\hline Growth & 8.5 & 1.3 & 14.6 & 2.7 & 1.7 & 3.7 & 4.5 & 4.4 & 4.4 \\
\hline AltPerf & 10.0 & 2.6 & 25.9 & 7.6 & 4.6 & 15.8 & 8.2 & 5.0 & 8.9 \\
\hline
\end{tabular}


TABLE 5: Value Relevance of Individual Accounting Amounts for New Economy, Non-New Economy Profit, and Non-New Economy Loss Firms (continued)

Panel B: Trends in value relevance by subsample

\begin{tabular}{|c|c|c|c|c|c|c|}
\hline & \multicolumn{2}{|c|}{ New Economy } & \multicolumn{2}{|c|}{ Non-NE, Profit } & \multicolumn{2}{|c|}{ Non-NE, Loss } \\
\hline & Trend & (t-stat) & Trend & (t-stat) & Trend & (t-stat) \\
\hline$N I$ & $-1.227 * * *$ & $(-8.73)$ & $-0.252 * * *$ & $(-2.86)$ & 0.000 & $(-0.01)$ \\
\hline$B V E$ & $0.290 * * *$ & (2.97) & $0.207 * *$ & $(2.60)$ & -0.017 & $(-0.10)$ \\
\hline$R D$ & -0.031 & $(-0.71)$ & -0.011 & $(-0.57)$ & 0.045 & (1.01) \\
\hline INTAN & $0.060 * * *$ & (7.29) & $0.048 * * *$ & $(7.29)$ & $0.043 * *$ & (2.34) \\
\hline$A D V$ & 0.000 & $(0.13)$ & -0.017 & $(-1.64)$ & -0.010 & $(-1.56)$ \\
\hline CASH & $0.219 * * *$ & $(4.58)$ & $0.021 * *$ & $(2.18)$ & 0.041 & $(1.02)$ \\
\hline$R E V G R$ & $0.143 * * *$ & (3.20) & $0.024 * * *$ & $(3.47)$ & 0.025 & (1.11) \\
\hline$C F$ & $0.442 * * *$ & $(5.01)$ & $0.197 * * *$ & (8.13) & $0.245 * * *$ & (3.33) \\
\hline$R E V$ & $0.067 * * *$ & (2.94) & $0.042 * *$ & (2.69) & -0.001 & $(-0.03)$ \\
\hline$S P I$ & $0.025 * * *$ & (3.61) & $0.037 * * *$ & $(3.47)$ & 0.012 & $(0.78)$ \\
\hline$O C I$ & -0.005 & $(-1.24)$ & 0.000 & $(0.00)$ & 0.006 & $(0.72)$ \\
\hline$D I V$ & $-0.088 * * *$ & $(-4.73)$ & $-0.114 * * *$ & $(-4.13)$ & -0.034 & $(-0.60)$ \\
\hline$C A P X$ & 0.015 & (1.09) & $0.031 *$ & (1.91) & $-0.266^{* * *}$ & $(-3.04)$ \\
\hline COGS & -0.062 & $(-1.51)$ & $-0.062 * * *$ & $(-2.89)$ & -0.015 & $(-0.42)$ \\
\hline$S G A$ & 0.012 & (1.04) & 0.013 & $(1.22)$ & -0.041 & $(-1.34)$ \\
\hline ASSETS & $0.139 * * *$ & (3.68) & $-0.147 * * *$ & $(-3.98)$ & -0.024 & $(-0.23)$ \\
\hline$I N D$ & 0.001 & $(0.07)$ & -0.017 & $(-1.57)$ & -0.007 & $(-0.27)$ \\
\hline Intans & 0.029 & $(0.63)$ & 0.020 & $(0.86)$ & 0.078 & (1.57) \\
\hline Growth & $0.362 * * *$ & $(4.07)$ & $0.045 * * *$ & $(3.33)$ & 0.066 & (1.58) \\
\hline AltPerf & $0.529 * * *$ & $(6.43)$ & $0.276 * * *$ & $(9.26)$ & $0.261 * * *$ & (3.27) \\
\hline
\end{tabular}


TABLE 5: Value Relevance of Individual Accounting Amounts for New Economy, Non-New Economy Profit, and Non-New Economy Loss Firms (continued)

This table presents value relevance of accounting amounts for subsamples. Panel A presents mean value relevance across time. Panel $\mathrm{B}$ presents trend in value relevance, estimates of $\beta_{1}$ from the following regression:

$$
V R_{t}=\beta_{0}+\beta_{1} Y E A R_{t}+\varepsilon_{t}
$$

$V R_{t}$ is the value relevance of a given accounting amount in year $t$, which is the share (in percent) of combined value relevance, and $Y E A R_{t}$ is fiscal year $t$. For groups of accounting amounts, Intans refers to sum of value relevance of RD, INTAN, and ADV, Growth refers to sum of value relevance of $C A S H$ and REVGR, and AltPerf refers to sum of value relevance of $C F, R E V, S P I$, and $O C I$. See Appendix 2.*,**, and $* * *$ indicate two-tailed significance at the 10, 5, and 1 percent levels. 